\title{
Evaluation of knowledge flow from developed to developing countries in small satellite collaborative projects: the case of Algeria
}

\author{
Authors: Ahmed Ayad ${ }^{*}$, Ron Matthews ${ }^{\mathrm{a}}$, Ivan Vitanov ${ }^{\mathrm{a}}$ \\ a Centre for Defence Management and Leadership, Cranfield University, Shrivenham, SN6 8LA, UK. \\ *Corresponding author. Tel: +44 (0) 1793785026 ; +213 (0) 552236648 \\ E-mail addresses: aayad@asal.dz; a.ayad@cranfield.ac.uk
}

\begin{abstract}
Technology transfer involves the flow of knowledge from technology developers or possessors to technology acquirers that benefit from the knowledge. This article proposes a model for the evaluation of knowledge flow in complex technology transfer projects from developed to developing countries. The proposed knowledge flow model is built by combining the concepts of knowledge viscosity and velocity with the concepts of architectural and component knowledge. The model rests on the idea that the transfer of knowledge to resource-limited organisations such as those in developing countries requires a balance between viscosity and velocity on one hand, and between architectural and component knowledge on the other. The knowledge flow model has been tested on data sourced from three Earth-observation small satellite collaborative projects leveraged by Algeria in order to acquire small satellite technology from abroad and build local capability. The implementation of the model revealed that the collaborative projects enabled only the acquisition of a shallow form of architectural knowledge detached from the local environment. The findings are reflective of the limitations of the collaborative projects mechanism and the challenge faced by the technology acquirer to strike the appropriate component/architectural and viscosity/velocity balance.
\end{abstract}

Keywords: small satellite technology transfer; technology transfer modelling; developing countries; complex technology transfer; knowledge flow.

\section{1- Introduction}

In the context of knowledge-based theory [1], this article examines knowledge flow in projects where complex technology is transferred from developed to developing countries. For the purpose of this study, technology transfer refers to knowledge generated in an organisation in a developed country and acquired by an organisation in a developing country, where the acquirer's intention is to build indigenous technological capability. The latter refers to the acquirer's "ability to make effective use of technological knowledge in efforts to assimilate, use, adapt and change existing technologies. It also enables one to create new technologies and to develop new products and processes in response to a changing economic environment." [7, p.4].

The knowledge-based approach is adopted in this study to transcend limitations of the traditional literature on international technology transfer and technological capability building. This literature remains highly influenced by a mono-dimensional economic perspective, where much of the evidence stems from studies related to mass-produced goods [73, 74, 75]. By contrast, the present study emphasises knowledge-intensive, complex, and one-off products, such as Earth observation small satellites, where the economic perspective is restrictive because the direct and immediate economic potential of earth observation satellites manufacturing is not yet proven and remains the least commercially driven segment in the satellite industry [76].

Complexity is one of the chief barriers to entry in the high technology industry. To circumvent the need to address complexity, some developing countries have forged ahead with programmes designed to acquire complex technology directly from developed countries in order to build local technological capability and generate local technological value. Many of these countries have not 
progressed beyond mere assembly (or screwdriver) operations. A few have succeeded in acquiring technology and building local technological capabilities, emerging as potential competitors to developed countries $[60,61,62]$. Given the lukewarm results after numerous attempts, this transfer process is a contentious yet topical subject, with implications for both developing and developed countries.

Developing countries take a two-pronged approach to technology transfer: firstly, acquiring technology from abroad, and, secondly, diffusing that technology locally. This article evaluates knowledge flow during the phase of technology acquisition from abroad. The acquisition occurs via collaborative projects in which the transferor and transferee teams are mixed for a limited time. The local diffusion of technology, which is not the focus of this article, occurs through post-collaborative projects knowledge transfer. The local diffusion of technology was evaluated as part of a broader empirical study aimed at evaluating small satellite technology transfer to Algeria, with the results presented in a separate publication [77].

This article decomposes the apparent complexity of the process of technology transfer during collaborative projects employing what is termed a knowledge flow model. The concepts of knowledge viscosity and velocity [2] are combined with the concepts of architectural and component knowledge [3] to evaluate knowledge flow in complex technology transfer projects. The model is in line with the resource-based view of the organisation [71], where knowledge is viewed as a resource at the core of developing and assembling other resources within the organisation [72]. The model rests on the idea that the transfer of knowledge to resource-limited organisations such as those in developing countries requires a balance between viscosity and velocity and also between architectural and component knowledge. To enhance the validity of evaluation, the model is based on theory 'triangulation', by the combination of two theoretical perspectives from which the typologies (Viscosity/Velocity and Architectural/Component) stem [65]. These dual perspectives contribute to the enrichment of the discipline of representing complexity, which is still in its infancy $[17,63,64]$.

The knowledge flow model is tested on the popular mechanism of international collaborative projects, as used to transfer Earth observation small satellite technology from developed to developing countries [4]. A few studies have focused on technology transfer in space (or satellite) technology, addressing the issue either from a developed-to-developed country perspective (i.e. technology transfer between organisations situated in developed countries) [55, 56], or a developed-todeveloping country perspective $[4,57,58]$. But none of these studies attempted to evaluate (or measure) the flow of transferred knowledge, even those studies grounded in knowledge-based theory [55].

The knowledge flow model is applied herein to three small satellite collaborative projects leveraged by Algeria in order to build local small satellite capability, where the satellites are micro- or minisatellites [51]. The purpose of this study is to evaluate and characterise the knowledge flow enabled by collaborative projects, and guide the transfer process whose success depends on a multiplicity of political, socio-economic and organisational factors, and combines exogenous and endogenous factors [78].

This article is organised as follows. Section 2 describes the knowledge typologies used to build the proposed model. Section 3 examines the characteristics of complex technologies, particularly technological systems called complex product systems (COPS). The core elements underpinning the creation of local value through the establishment of a complex technology supply chain in developing countries are discussed in Section 4. The proposed knowledge flow model is formulated in Section 5 and applied in the context of small satellite technology transfer to Algeria in Section 6. Sections 7 and 8 discuss the findings resulting from the application of the knowledge flow model and offer concluding remarks and a set of recommendations.

\section{2- Knowledge flow in a technological context}


Knowledge flow is addressed herein by combining two distinct knowledge typologies. The first is drawn from the concepts of knowledge velocity and viscosity [2]. These concepts are rarely operationalised in the technology management and innovation literature, and a systematic literature review identified only one set of researchers making partial operationalisation of these concepts in two published papers $[5,6]$. In terms of nomenclature, velocity refers to the "...speed with which knowledge moves through an organisation. How quickly and widely is it disseminated? How quickly do the people who need the knowledge become aware of it and get access to it?" [2, p.102]. Viscosity in turn represents the "...richness (or thickness) of the knowledge transferred. How much of what we try to communicate is actually absorbed and used? To what extent does the original knowledge get pared down? Does what was absorbed bear little resemblance to what we tried to transmit and retain little of its original value?" [2, p.102].

Information and communication technology (ICT) enhances knowledge velocity, whereas factors such as the transfer mode influence viscosity [2]. A knowledge transfer mode that fosters a lengthy process of apprenticeship or the formation of a mentoring relationship enhances the depth or viscosity of knowledge through subtle knowledge sharing. Viscosity is reduced if knowledge is made accessible only via scientific journals or online databases [59]. The absorption of new knowledge in technology transfer is a slow, sometimes long and laborious process [2,8]. Successful knowledge transfer requires a delicate balance between velocity and viscosity, which tend to be inversely proportional [2]. Indeed, the adopted transfer mode generally represents a compromise between high velocity and acceptable viscosity [59, p.159].

The delicate balance between velocity and viscosity required for effective transfer is closely tied to the nature of the knowledge and the actors involved in its transfer. In a technological and industrial context, knowledge is very often thought of as a resource that includes two complementary components: tacit and explicit knowledge $[9,10]$.

Another typology that is relevant in a technological context is the division between component knowledge, relating to the core design concepts for each component of the product, and architectural knowledge relating to the manner in which components are put together to form the system or product [3]. With technology-oriented industries in mind, component knowledge has been described as "relatively coherent and definable, and ... usually acontextual" [11, p.264]. Component knowledge remains subject to incremental changes and is managed explicitly [3], and therefore has the potential to be transferred to informed learners [11, 12]. However, the flow remains dependent on the explicitness of the knowledge, and whether it is simple or complex, independent or systemic, and tangible or intangible $[13,14]$. Component knowledge is considered to be related to subroutines or parts of the organisation's operations rather than the whole [15]. Both individuals and groups within the organisation can hold this type of knowledge.

Unlike component knowledge, architectural knowledge refers to "organisation-wide routines and schemas for coordinating the various components of the organisation and putting them to productive use" [15, p684]. Architectural knowledge is built collectively over time, shaped by idiosyncratic events within the organisation and its evolutionary path, and is built by encouraging interactions $[16,53]$. This knowledge is typically complex, intangible, tacit, and organisation-specific, which makes it difficult to transfer [11]. Baldwin [17] stressed that architectural knowledge is a function-centred concept. It includes "knowledge about how the system performs its functions (the function-to-component mapping)" (p.3), knowledge about "how the components are linked together (i.e. through interfaces)" (p.4), and knowledge about how the system performs or behaves in both planned and unplanned situations and in different environments.

Architectural knowledge originates from the design $[33,17]$ so it is dynamic and intense at the beginning of the design phase [40]. Once the design of a technological system is accepted (dominant design), architectural knowledge becomes stable and implicitly embedded in the organisation [3]. Stability in this context does not mean rigidity because a dominant design can still be subject to 
modifications. Tasks conducted during the advanced stage of system assembly, integration and test/verification (AIT/AIV) can identify design deficiencies requiring corrective action, particularly when the AIT/AIV approach is incremental, conducted from the outset and throughout the project [20, p.364-370]. AIT/AIV tasks are generally carried out when there is sufficient insight into the conceptual, preliminary or detailed design [30, p.160-191, 42]. In this article, AIT/AIV knowledge is described as integrative knowledge, or a form of architectural knowledge. AIT/AIV or integrative knowledge, like architectural knowledge, is inherently functional because it targets the system as a whole that performs its functions and it relates to the design because it can guide design modifications. In this article, we consider AIT/AIV knowledge in the context of complex technology transfer project from developed to developing countries, where the knowledge shared (or transferred) is mainly related to AIT/AIV $[4,30,62]$.

In order to acquire technology, the literature on strategy and innovation suggests that organisations with limited resources (including knowledge), such as those in developing countries, need to make a trade-off between architectural and component knowledge. The trade-off is not easy, because these concepts are entangled and influence each other $[3,17]$. Indeed, faced with the inherent complexity of a technological system, the organisation can engage deliberately in a multitude of strategies, combining both architectural and component knowledge $[17,19]$. It can also be dragged inadvertently towards a kind of exclusivism [17]. It may be so focused on building architectural knowledge (through integrative capabilities) that component knowledge is neglected, or the quest for component knowledge may lead to the neglect of architectural knowledge. For simplicity, this article considers the interplay between architectural and component knowledge without considering their mutual influences in detail. Based on transaction cost economics, small firms (with a limited scope of resources, including knowledge) may generate autonomous innovation more efficiently than large companies (possessing a larger scope of resources, including knowledge) [18]. Such innovation relates to the development of new components that fit comfortably into the existing system. Conversely, large firms are better placed for the development of systemic innovation, which relates to new architectures and thus leads to further coordination problems.

In similar vein, Jacobides and Winter [19] show that the optimal choice for firms with financial constraints is to narrow their initial scope. Baldwin [17] recognises the difficulty of striking the right balance and proposes a strategy in which resource-limited firms narrow their initial scope by focusing on learning internally about certain components, i.e. crucial components, sometimes called 'bottleneck' components, and outsourcing non-bottleneck components. From a systems engineering perspective, a system with $n$ components may require up to $n^{2}$ interfaces that need to be considered in the design [54] and ultimately integrated and tested [20, p.362]. Thus, if the number of components increases (which may be regarded as an increase in component knowledge), coordination problems increase by corollary (which may be regarded as a decrease in architectural knowledge). Consequently, the literature acknowledges the inversely proportional relationship between the number of components (or component knowledge) and architecture knowledge in resource-limited firms. A similar situation exists with respect to the delicate balance sought between velocity and viscosity to achieve successful knowledge transfer.

\section{Why combine the two typologies (velocity/viscosity and component/architecture)?}

Combining the two typologies deploys multiple theoretical perspectives (or theory triangulation) ${ }^{1}$ in the same evaluation study in order to improve validity [65] as one perspective's strengths can offset another's weaknesses. As the present evaluation lies within the knowledge-based tradition [1], the proposed approach primarily examines knowledge flow, or learning, in which complex technology is transferred. Knowledge is more than data and information [68]; It is rather a continuous "fluid mix of

\footnotetext{
1 Triangulation is used to improve the validity of a study. Theory triangulation refers to the use of multiple theoretical perspectives. Three other basic types of triangulations are identified: Data triangulation, Methodological triangulation, and Investigator triangulation [65].
} 
framed experience, important values, contextual information, and expert insight" [68, p205], while data are discrete facts, with information constructed around a body of data [2]. Knowledge has different dimensions, and knowledge flow in technology transfer goes beyond technological considerations, as the social organisation matters [68,69]. Davenport and Prusak's typology captures this inclusive definition of knowledge and can be used to characterise the flow (through velocity and viscosity) regardless as to whether the knowledge flows in a technological system (e.g. between components of a technological systems) or within a social organisation (e.g. between individuals within a group, functions or departments within an organisation) $[6,68]$. This is particularly important when the type of knowledge is complex, systemic and has a significant tacit dimension $[2,68]$. Moreover, Davenport and Prusak's typology, with suitable adaptations (as shown in the proposed model), captures further dimensions in the knowledge flow such as the breadth and depth of the transferred knowledge.

On the other hand, Henderson and Clark's typology (Architecture/Component) derives from the concept of modularity [33]. "Modularity is based on relationships among structures, not functions" [40, p63]. The typology Architecture/Component was built on the assumption that organisations possess bounded rationality and their formal structure mirrors the internal structure of the product [3]. It is built by "taking as the unit of analysis a manufactured product" [3, p10], and by making "This distinction between the product as a whole - the system - and the product in its parts - the components-“ $[3, \mathrm{p} 11]$. This typology is therefore product-centred ${ }^{2}$ and not necessarily 'knowledgecentred'. An attempt to bypass Henderson and Clark's typology limitation is made through combining this approach with the typology of Davenport and Prusak, because of the need to focus on knowledge flow.

The present study attempts to evaluate knowledge flow quantitatively, which has always been a question that needs to be addressed in social sciences $[6,66]$. Each knowledge area requires its own heuristic methods to evaluate knowledge quantitatively [67]. In this respect, Davenport and Prusak's knowledge-centred typology has rarely been operationalised $[5,6]$ and lacks maturity. However, the product-centred perspective of Henderson and Clark's typology has been operationalised in several studies, employing a generation of methods, approaches, tools and techniques $[3,17,33]$. The present study offers an alternative intermediate way that combines some of the strengths of the product-centred approach to bypass some of the weaknesses of the knowledge-centred approach and vice-versa. For instance, it borrows techniques from the product-centred operationalisation approaches and applies them in order to operationalise some facets captured by knowledge-centred approach. It can therefore open up the debate on the operationalisation of knowledge velocity/viscosity concepts.

\section{3- Complexity of technological systems}

Complexity poses one of the main barriers to entering advanced and high-technology industries. Successful transfer of high technology requires that the transferee learns how to effectively manage complexity, which is seen as a socio-cultural phenomenon reflecting interactions among products, processes and organisations [21, p.57]. Drawing on this perspective, a group of scholars led by Hobday and Rush [22] recognised the peculiarities of certain technological activities characterised by complexity, and laid down a number of principles for a new holistic approach known as complex product systems (COPS). This approach goes beyond a purely technical understanding and includes managerial and political considerations. Hobday [23] defines CoPS as "high-cost, engineering-intensive products, systems, networks and constructs" (p.690) and explains that CoPS are often produced "in one-off projects (or small batches) and the emphasis of production is on design, project management, systems engineering and systems integration" (p.690).

\footnotetext{
${ }^{2} \mathrm{~A}$ product can be a physical good, an intangible good, or a service
} 
Three important aspects describe the complexity characteristics of a product. The first is the number of components we need to know about, which relates to the diversity (or breadth) of component knowledge that the system integrator requires [24]. In this respect, we should not overlook the depth of knowledge associated with each component, which is the knowledge required to generate it [24, 25]. Indeed, the components of complex systems are not simple components but are in themselves architectures (e.g. modules or subsystems) connecting the sub-components. Therefore, components as knowledge-gathering entities can be seen as a microcosm of the larger system, because they share common features with it. The second aspect of complexity refers to the level of proficiency (or depth) needed to manage the interdependencies between components. This is the concern of architectural knowledge [17]. The third aspect relates to the novelty of the knowledge required to build a complex system, and it concerns both component and architectural knowledge. Indeed, acquiring new knowledge hinges largely on the absorptive capacity of learners [26]. This can be broken down into the abilities enabled by prior knowledge (i.e. knowledge accumulation) and the intensity of the learning effort. The intensity of organisational effort, through actions leading to both continuous and discontinuous learning, is proposed to have a more prominent role than prior knowledge, particularly for long-term learning [27].

Davies [28] and Hobday [23] propose categories of products that might be classed as CoPS. They explain that standalone products such as satellites, which are made of interconnected components, can be considered as CoPS. Consequently, a CoPS framework has been used to analyse satellite projects. Moody and Dodgson [29] draw heavily on the CoPS approach to analyse a small satellite collaborative project in Australia. Wood [30, p.78] considers the managerial challenges related to a CoPS project in exploring technological capability-building within satellite programmes in developing countries.

\section{4- Building a supply chain for a complex product in developing countries}

Organisations acquiring technology in developing countries do not act alone but operate in a network of other actors that influence their activities. Lundvall [31] argued that interactions with these actors can largely explain the effectiveness of knowledge transfer. In the context of complex technology, the effectiveness of knowledge transfer is reflected in the local value created, stemming in particular from a well-established supply chain [32, p.20]. CoPS often require the coordination of several producers working together, but the density and continuity of interactions often prove insufficient. Baldwin [17] claims that the technical architecture of complex systems shapes the strategy of the organisation and determines whether parts of the system are insourced or outsourced. Based on modularity theory [33 p.7], Baldwin [17] claims that the knowledge flow between an organisation and its suppliers is influenced by the system architecture (i.e. architectural knowledge) and particularly by the strength of the coupling between its components (i.e. component knowledge). It is less complicated to outsource production when the coupling is loose, whereas production is often insourced when the coupling is strong.

Furthermore, the knowledge that enables the organisation to make the choice between outsourcing and insourcing has its roots in the product's architectural knowledge. This originates from knowledge of the product design $[33,17]$, which means that it emerges during the design phase of the project and then "become[s] embedded in the structure and information-processing procedures of ... [the] organisation" [3, p.9]. This knowledge is not confined to the organisational level, but thrives on interorganisational interactions [11].

Weak interactions are a major handicap in developing countries, mostly because of institutional barriers, the lack of flexibility and cumbersome procedures [34,35]. On the other hand, in the context of complex technology transfer, the technological product which is transferred is often the result of a pre-existing stable and accepted design, known as the dominant design, developed by the transferor over a long period of time [3]. Given the high value of the design, sharing the related knowledge (i.e. 
architectural knowledge) with any third party (e.g. partner, customer or supplier) is extremely difficult, because it might fuel competition and constitute a threat [36, 37].

The sourcing decision also depends on the complexity of the individual components or modules [38]. The challenge posed by the architectural knowledge of those components can be viewed similarly to that of the main system. Further consideration should be extended to the trade-off between using custom or standard sub-components (e.g. off-the-shelf components). Ulrich and Ellison [39] and Baldwin and Clark [40] discussed this trade-off along with some other factors that influence the sourcing decision, including cost, performance and production, or simply integration. Novak and Eppinger [38] highlighted the wide range of possibilities reflected in the complexity of the sourcing decision, and thereby the complexity of building a supply chain for complex products.

\section{5- The proposed model}

This section brings together the concepts presented in Sections 2 and 3 to form a knowledge flow model that can be used to evaluate the transfer of complex technology from developed to developing countries. Building on the knowledge typology of Henderson and Clark [3] and on complex technology characteristics [22], it can be postulated that the successful transfer of a technological system is akin to effective learning in respect of the system architecture and components. The technology acquirer should therefore acquire the knowledge that relates to the core design concepts of each component, and to the architectural knowledge required to put together (or integrate) these components to form a system. Even though integration is only a form of architectural knowledge (as explained in Section 2 ), it is more practical to use the terms architectural and integrative knowledge interchangeably, particularly during the implementation of the model.

In accordance with the systems engineering view, a technological system is a decompositionintegration process. A technological system is an architecture gathering together various components, and each component is further decomposed into sub-components. The decomposition continues down to the lowest level (e.g. hardware, software). On the other hand, the lowest-level entities are integrated together, validated and tested to form higher-level entities, and the process flows up to the systems level. The selection of the decomposition approach is often driven by the need to integrate, upgrade, and develop more easily, or to simplify management accountability [20].

To explain the proposed model, a product breakdown structure (PBS) is used to illustrate the decomposition-integration process associated with the transfer of a technological system (Figure 1). System complexity is highlighted by the multiple levels of decomposition and the number of components at each level.

Figure 1: Component and architectural (integrative) knowledge in the product breakdown structure 


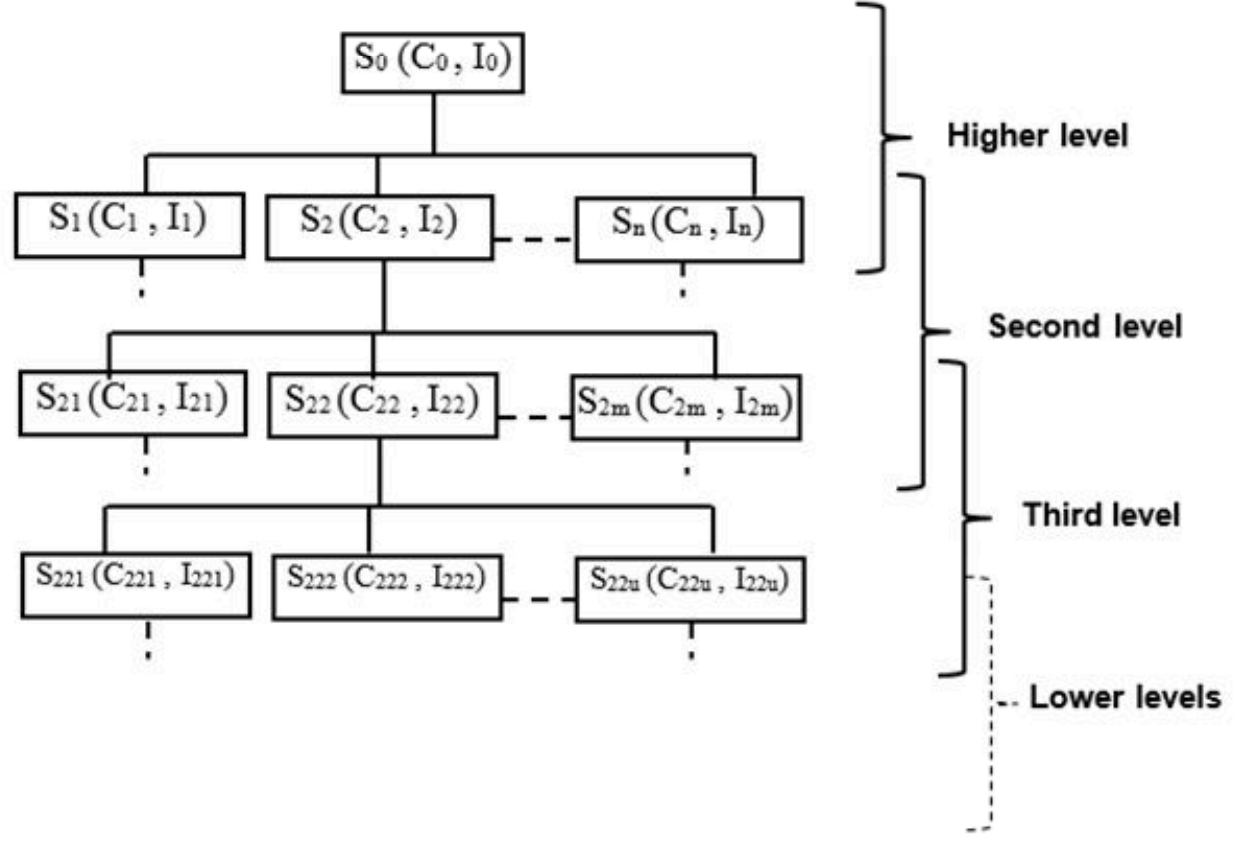

Source: Authors.

Let $\mathrm{S}$ denote the components of the technological system. At the highest level, $\mathrm{S}_{0}$ denotes the final integrated product (or the technological system). $S_{1}, S_{2}, \ldots, S_{n}$ denote sub-components of $S_{0}$. At the second level, $S_{i 1}, S_{i 2}, \ldots, S_{i m}$ denote sub-components of $S_{i}$. At the third level, $S_{i j 1}, S_{i j 2}, \ldots, S_{i j u}$ denote subcomponents of $S_{i j}$, and so on until the lowest level of decomposition is reached. ${ }^{3}$ For example, the systems engineering handbook of the International Council on Systems Engineering-INCOSE defines seven decomposition levels: system, segment, element, subsystem, assembly, subassembly and part [41].

Based on the knowledge typology of Henderson and Clark [3], it is posited that each component of the technological system can be related to two types of knowledge: component knowledge $\mathrm{C}$ and integrative (or architectural) knowledge $I$. The pair $\left(C_{0}, I_{0}\right)$ refers to component and integrative knowledge related to component $S_{0} .\left(C_{1}, I_{1}\right),\left(C_{2}, I_{2}\right), \ldots,\left(C_{n}, I_{n}\right)$ therefore refer to the component and integrative knowledge related to components $S_{1}, S_{2}, \ldots, S_{n}$. At the second level, $\left(C_{i 1}, I_{i 1}\right),\left(C_{i 2}, I_{i 2}\right), \ldots$, $\left(C_{i m}, I_{i m}\right)$ refer to the component and integrative knowledge related to components $S_{i 1}, S_{i 2}, \ldots, S_{i m}$. At the third level, $\left(C_{i j 1^{1}}, l_{i j 1}\right),\left(C_{i j 2}, l_{i j 2}\right), \ldots,\left(C_{i j u}, l_{i j u}\right)$ refer to component and integrative knowledge related to components $\mathrm{S}_{\mathrm{ij} 1}, \mathrm{~S}_{\mathrm{ij} 2}, \ldots, \mathrm{S}_{\mathrm{iju}}$.

There is an assumption that component knowledge $C$ of any component is the entire knowledge that is needed in order to build this component. This is the combination of the knowledge of its constituent elements (or its sub-components) along with the knowledge required to integrate these elements. In other words, the knowledge that needs to be acquired (or transferred) in order to build the component is simply its component knowledge. Let KT denote the knowledge acquired (or transferred), then for each component of the system:
$\mathrm{KT}_{0}=\mathrm{C}_{0}=\mathrm{C}_{1}+\mathrm{C}_{2}+\ldots .+\mathrm{C}_{\mathrm{n}}+\mathrm{I}_{0}$
(1), where $C_{1}, C_{2}, \ldots, C_{n}$ refer to sub-component knowledge and $I_{0}$ is the knowledge required to integrate these sub-
components.

\footnotetext{
${ }^{3} n, m$ and $u$ refer to the numbers of components at each level of decomposition.
} 
$\cdots$

$\mathrm{KT}_{2}=\mathrm{C}_{2}=\mathrm{C}_{21}+\mathrm{C}_{22}+\ldots .+\mathrm{C}_{2 \mathrm{~m}}+\mathrm{I}_{2}$

$\mathrm{KT}_{22}=\mathrm{C}_{22}=\mathrm{C}_{221}+\mathrm{C}_{222}+\ldots .+\mathrm{C}_{22 \mathrm{u}}+\mathrm{I}_{22}$

The proposed model illustrates the interplay between component and architectural knowledge during technology transfer. The flow of knowledge from transferor to transferee can be viewed differently by borrowing the concepts of knowledge viscosity and velocity. As discussed in Section 2, Davenport and Prusak's [2] typology, with suitable adaptations in order to operationalise concepts rarely operationalised in the technology management and innovation literature, captures further dimensions in the knowledge flow such as the breadth and depth of the transferred knowledge. For the purposes of the model, viscosity refers to the flow, in terms of depth of knowledge transferred, and it specifically provides an indication of the depth of integrative (or architectural) knowledge required to put components together. Let KVis denote the volume or quantity of knowledge that flows as a result of viscosity, ${ }^{4}$ then:

$\mathrm{KVis}_{0}=\mathrm{I}_{0}$

$\mathrm{KVis}_{2}=\mathrm{I}_{2}$

$\cdots$

$\mathrm{KVis}_{22}=\mathrm{I}_{22}$

(4) (This equation shows the link between viscosity and architectural knowledge)

(6)

On the other hand, velocity refers to the speed with which knowledge moves during a technology transfer project. For the purposes of the model, it is posited that the knowledge which moves during the lifetime of a project can be gathered into knowledge blocks formed according to subjects. Each subject (or knowledge block) relates to one component. Let assume that the lifetime of a project corresponds to one unit of time. If during a lifetime of a project (or one unit of time), the technology acquirer learns about $n$ knowledge blocks or components, the velocity can refer to the volume (or quantity) of the $n$ knowledge blocks that moves during one unit of time (project lifetime). Velocity, therefore, provides an indication as to the number of subjects (or components) learned about during the course of the project and the corresponding volume (or quantity) of knowledge. In other words, velocity provides an indication of the breadth of component knowledge transferred. This knowledge is reflected in the quantity and/or diversity of component knowledge transferred and, implicitly, the depth of knowledge associated with each component. Let KVel denote the volume or quantity of knowledge that flows as a result of velocity, ${ }^{5}$ then:
$\mathrm{KVel}_{0}=\mathrm{C}_{1}+\mathrm{C}_{2}+\ldots .+\mathrm{C}_{\mathrm{n}}$
(7) (This equation shows the link between velocity and component knowledge)

\footnotetext{
${ }^{4}$ Caveat: KVis is not the viscosity, it refers to the knowledge that flows as a result of viscosity.

${ }^{5}$ Caveat: KVel is not the velocity, it refers to the knowledge that flows as a result of velocity.
} 
$\mathrm{KVel}_{2}=\mathrm{C}_{21}+\mathrm{C}_{22}+\ldots . .+\mathrm{C}_{2 \mathrm{~m}}$

(8)

$\mathrm{KVel}_{22}=\mathrm{C}_{221}+\mathrm{C}_{222}+\ldots . .+\mathrm{C}_{22 \mathrm{u}}$

The knowledge transferred is a combination of two inversely proportional factors: breadth and depth (or knowledge resulting from velocity and knowledge resulting from viscosity, respectively). Figure 2 shows this delicate balance. The depth of integrative (architectural) knowledge is indicated in Figure 2 along the vertical y axis. The breadth of component knowledge is indicated in Figure 2 along the horizontal $x$ axis. The authors argue that the knowledge acquired for any component varies along the curve labelled set of combinations in Figure 2. Consequently, the knowledge transferred (KT) for each component of the system is given by:

$\mathrm{KT}=\mathrm{KVis}+\mathrm{KVel}$

Figure 2: Velocity vs viscosity (breadth vs depth) of knowledge

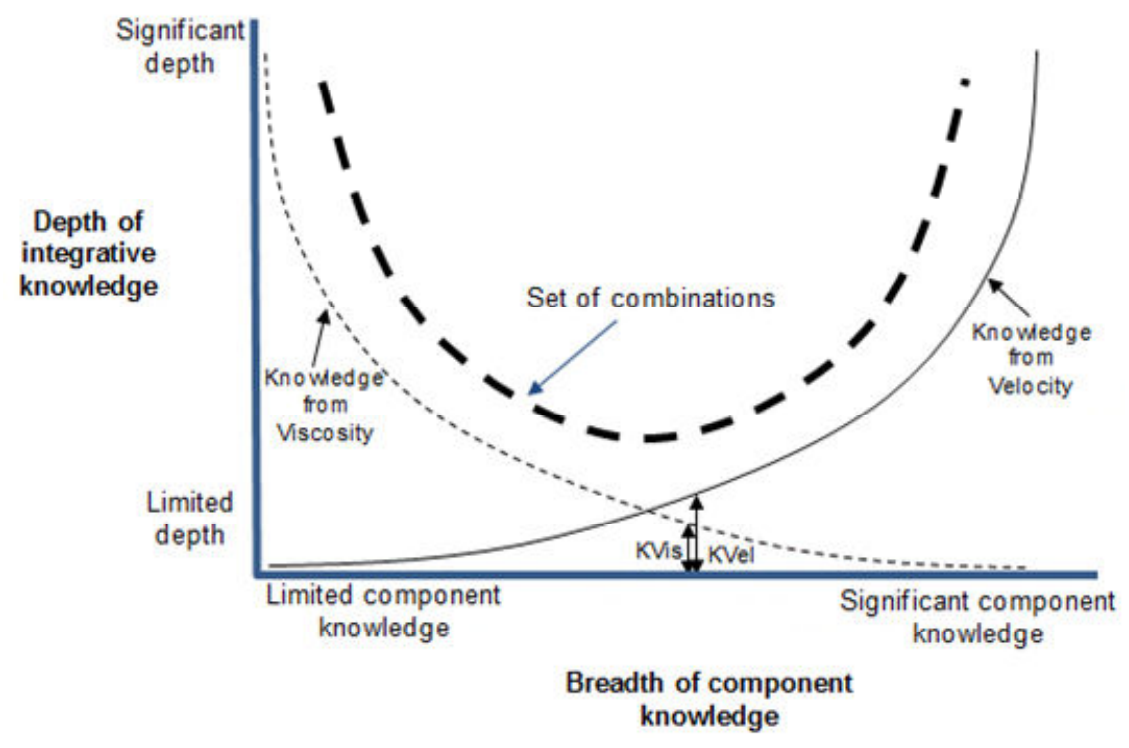

Source: Authors.

It is noteworthy that the velocity-viscosity balance is sought across all of the components of the technological system and at all levels of decomposition-integration (Figure 3). The knowledge transferred through each component can thus be represented by an equation combining two variables $\mathrm{KVis}$ (knowledge resulting from viscosity) and KVel (knowledge resulting from velocity):

$\mathrm{KT}_{0}=\mathrm{KVis}+\mathrm{KVel}_{0}$

$\mathrm{KT}_{2}=\mathrm{KVis}_{2}+\mathrm{KVel}_{2}$

$\mathrm{KT}_{22}=\mathrm{KVis}_{22}+\mathrm{KVel}_{22}$ 
The accumulation of balancing games, ${ }^{6}$ along with the reciprocal effect between components, reflects the challenge of effective knowledge acquisition. This is particularly relevant in the context of technology transfer, where balancing choices are insufficiently well informed because of initial constraints on the knowledge acquirer (i.e. developing countries), such as insufficient prior knowledge.

Figure 3: Velocity vs viscosity throughout the product breakdown structure

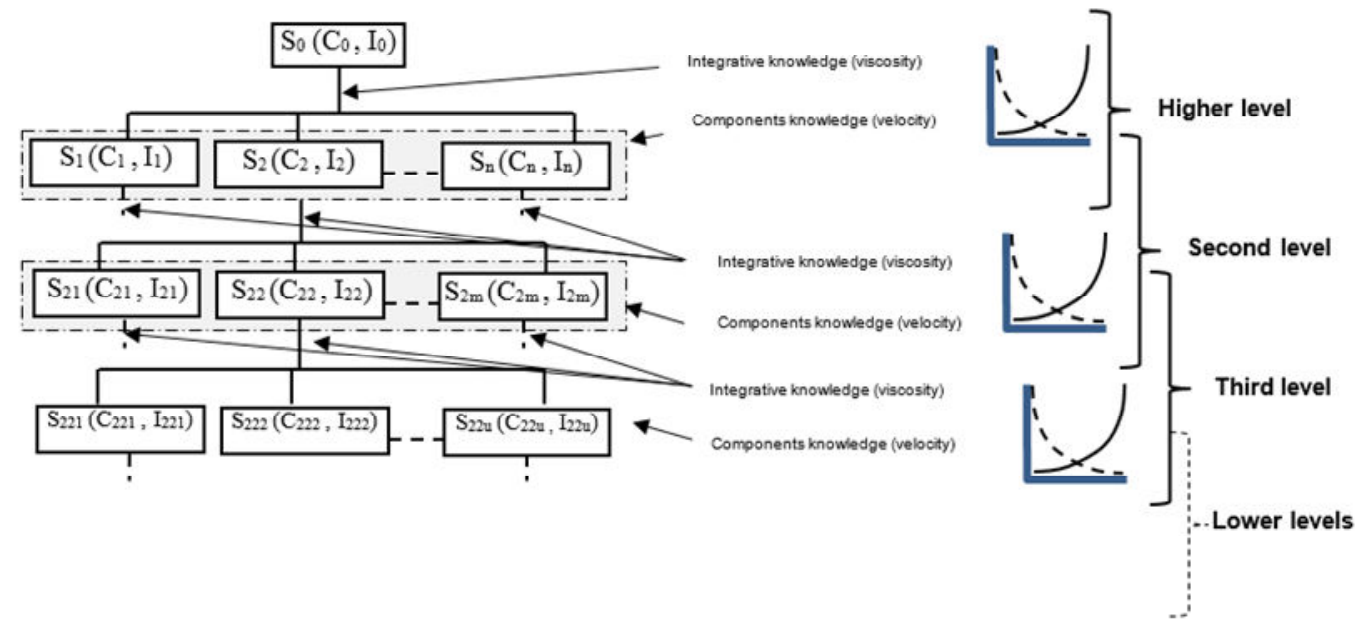

Source: Authors.

\section{Interplay between component and architectural knowledge}

In the interplay between component and architectural (or integrative) knowledge, the technology acquirer's objective is assumed to be maximisation of transferred knowledge. It is therefore clear from Equation (11) that an increase in knowledge transfer $\left(K T_{0}\right)$ related to the technological system requires a corresponding increase in either the depth of knowledge ( $\left.\mathrm{KVis}_{0}\right)$ or the breadth of knowledge $\left(\mathrm{KVel}_{0}\right)$ given the inverse relationship between these factors.

The first scenario is to increase the depth of knowledge (KViso) which implicitly means the depth of integrative knowledge. This knowledge can increase up to a point, but beyond a certain threshold the extent of component knowledge impedes further deepening [3]. In other words, it offers a margin for progress, but remains limited because it cannot go beyond a certain level of integration unless more is known about the components. Consequently, in order to know more about the components, there is a need to explore the second scenario.

The second scenario is to increase the breadth of knowledge $\left(\mathrm{KVel}_{0}\right)$, which implicitly means knowledge about the components. From equation (7), an increase in $K V_{\text {elo }}$ requires an increase in $\mathrm{C}_{1}$, $C_{2}, \ldots$, or $C_{n}$. Component $C_{2}$ is considered as an example.

Equation (2) shows that increasing the knowledge about component $C_{2}$ requires more knowledge about its sub-components $\mathrm{C}_{21}, \mathrm{C}_{22}, \ldots, \mathrm{C}_{2 \mathrm{~m}}$, which is equivalent to $\mathrm{KVel}_{2}$ (Equation (8)) or its integrative knowledge $\mathrm{I}_{2}$, which is equivalent to $\mathrm{KVis}_{2}$ (Equation (5)). KVis 2 remains limited and cannot go beyond

\footnotetext{
${ }^{6}$ The concept of 'balancing games' is borrowed from game theory to show the difficulty of seeking the balance between velocity-viscosity [79].
} 
a certain threshold because it is bound to the sub-components. $\mathrm{KVel}_{2}$ and $\mathrm{KVis}_{2}$ are inversely proportional, so as $\mathrm{KVel}_{2}$ increases, $\mathrm{KVis}{ }_{2}$ decreases, and vice versa. Likewise, the example of increasing knowledge about one of $C_{2}$ 's sub-components $\left(C_{22}\right)$ is examined below.

Equation (3) indicates that an increase in knowledge about sub-component $\mathrm{C}_{22}$ requires an increase in knowledge about its sub-subcomponents $\mathrm{C}_{221}, \mathrm{C}_{222}, \ldots, \mathrm{C}_{22 \mathrm{~m}}$, which is equivalent to $\mathrm{KVel}_{22}$ (Equation (9)) or its integrative knowledge $\mathrm{I}_{22}$, which is equivalent to $\mathrm{KVis} 22$ (Equation (6)). Similarly, KVis 22 remains limited and cannot rise above a certain threshold, because it is bound to the subsubcomponents. Furthermore, $\mathrm{KVel}_{22}$ and $\mathrm{KVis}_{22}$ are inversely proportional. In order to increase knowledge, the same rationale can be applied down to the lowest level of decomposition.

It is clear from the above that intra-level factors are interwoven. For example, integrative knowledge at one level depends on the component knowledge at the same level. Likewise, inter-level factors are related to each other, given that any attempt to increase knowledge about a single component requires a corresponding knowledge increase at lower levels (i.e. among the sub-components). The challenge is even greater when it comes to increasing knowledge about several components.

Graphically, the range of balancing options offered to the technology acquirer is represented in Figure 2 by the curve labelled set of combinations. In other words, any technology acquirer making the tradeoff to increase either depth of knowledge ( $\mathrm{KVis}_{0}$ ) or breadth of knowledge $\left(\mathrm{KVel}_{0}\right)$ will likely have to traverse this curve. The challenge of disentangling component knowledge and integrative knowledge suggests that a third scenario can be adopted in order to increase transferred knowledge, i.e. $\mathrm{KT}_{0}$ (see Equation (11)). This involves increasing both the depth of knowledge (KViso) and the breadth of knowledge (KVelo), or increasing one of them without decreasing the other.

Because the two factors are inversely proportional, increasing both factors simultaneously is only possible by achieving the kind of shift represented in Figure 4. Such a shift is achieved through structural, multi-dimensional and systemic measures (e.g. creating an innovative environment, investing in education, fostering collaborative work, or improving absorptive capacity of learners) involving political, socio-economic and organisational factors. At a project level, the shift could be implemented by improving the prior knowledge of the transferee's engineers (e.g. academic and professional background, preparatory activities ahead of the project, appropriateness of knowledge compared to requirements) and intensity of effort they invest in the learning process (e.g. appropriateness of effort for tacit or explicit learning, and incentives).

Figure 4: Increasing knowledge breadth and knowledge depth 


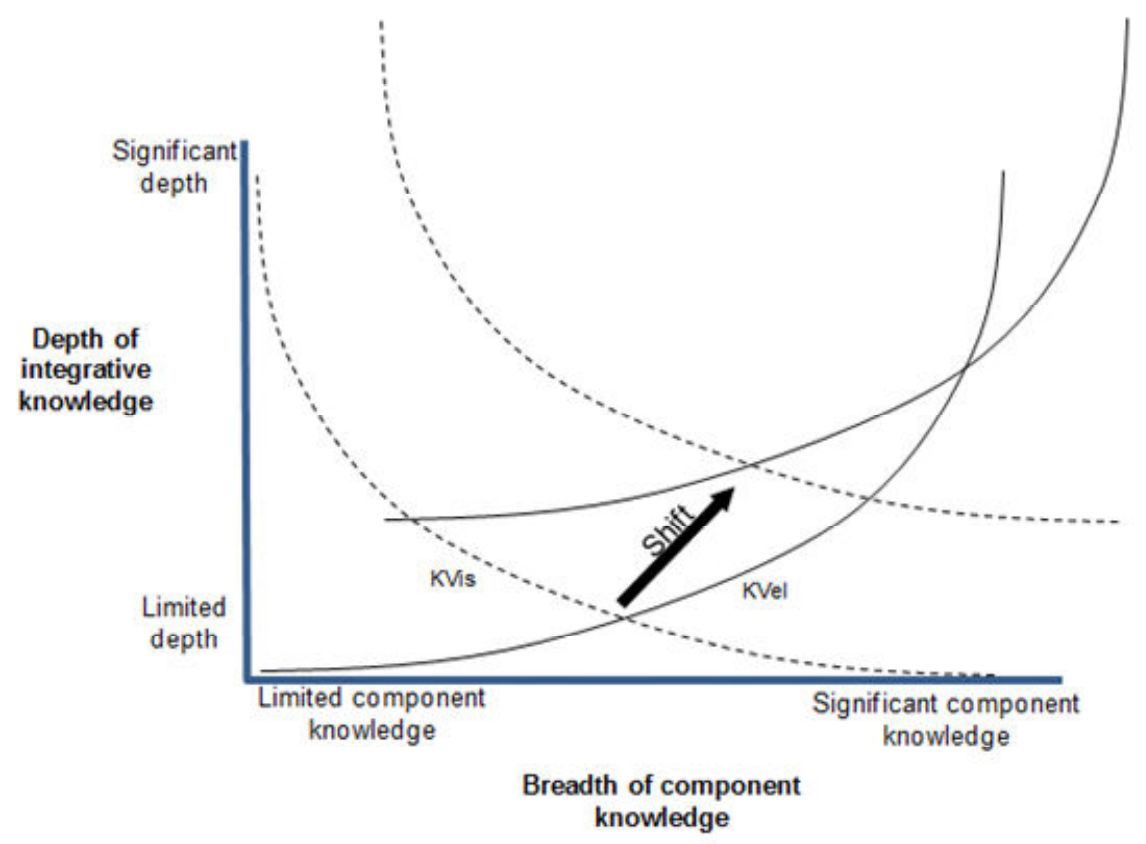

Source: Authors.

\section{6- Applying the model to small satellite technology transfer to Algeria}

The knowledge flow model formulated in Section 5 can be used to evaluate complex technology transfer from developed to developing countries. It was tested as part of a broader empirical study aiming to evaluate small satellite technology transfer to Algeria. Since the early 2000s, Algeria has used the mechanism of collaborative projects in order to build up its small satellite capabilities. The question that currently arises is how effective were collaborative projects?

The model was applied to three collaborative small satellite projects (Alsat-1, Alsat-2, and Alsat-1B) used by the Centre for Satellite Development (CSD), one of the Algerian Space Agency's affiliates, to acquire small satellite technology and build local capabilities. The declared objective of CSD is to build local capabilities to integrate satellites (but with no further detail on the nature of these capabilities). Alsat $-1^{7}$ and Alsat- $1 B^{8}$ are small satellites built in 2000 and 2014, respectively, in conjunction with SSTL-UK. They were launched in 2002 and 2016, respectively. Alsat-2 is a pair of identical satellites (Alsat-2A and $-B)^{9}$ built jointly with Airbus-France. The Alsat-2 project is perceived as one system, because most project phases began in 2005 and involved both satellites. Alsat-2A was completed and launched in 2010, whereas the integration and test phase of Alsat-2B commenced in 2012. Alsat-2B was launched in 2016. The selection of the partners (SSTL, Airbus) was based, inter alia, on satellites built using approved technologies with a proven space heritage. Satellite projects are generally conducted as per two major phases: (i) the design (Mission analysis/needs identification, Feasibility, Preliminary Definition, Detailed Definition), and (ii) implementation (Manufacturing (or procurement), Assembly and Testing, Launch and operations, Disposal) [20]. The design knowledge was not the focus of the collaborative projects under study because projects involved mature technologies inherited from previously approved designs. Algerian engineers were involved only in the implementation phase.

\footnotetext{
${ }^{7}$ Alsat- 1 is classed as a micro-satellite (mass $=92 \mathrm{~kg}$ )

${ }^{8}$ Alsat-1B is classed as a mini-satellite (mass $=110 \mathrm{~kg}$ )

${ }^{9}$ Alsat-2A and Alsat-2B are classed as mini-satellites (mass $=120 \mathrm{~kg}$ )
} 
Algerian engineers involved in the projects were selected according to their academic (selection of recent top graduated engineers) and professional backgrounds. For each project, a new team was formed of engineers with no previous experience in satellite projects. It was CSD choice to expand the number of its engineers possessing certain experience in satellite projects. Each team was managed by an engineer selected from the previous project. Preparatory activities were conducted ahead of projects in order to assign a role to each member. The study evaluated this aspect by measuring the prior knowledge possessed by engineers. Prior knowledge is measured by evaluating the appropriateness of academic and professional backgrounds of participants in the project, the appropriateness of preparatory activities ahead of the project, and the appropriateness of knowledge possessed to requirements during the project (through the Likert scales).

The collaborative mechanism applies to projects where a combination of academic and hands-on technical training was provided to the client's engineers [4]. During the implementation phase with Algerian Space Agency, the academic teams ${ }^{10}$ were separated from the hands-on technical teams. The latter received some lecture-based classes, and then spent time working together as teams with supplier engineers to build and launch the satellite. The mentoring provided by the supplier's engineers enabled the client's engineers to commence work on complex systems and to acquire and hone the diverse set of skills required for satellite development. The knowledge flow model was applied to the project teams involved in hands-on technical training (through mentorship).

\section{6-a- Data collection}

A mixed-method quadrilateral data acquisition method was used, incorporating four mutually reinforcing methods: secondary data, structured/semi-structured interviews, semi-structured/indepth interviews, and participant observation. Staged fieldwork was conducted in three campaigns, spread over a 13-month period from April 2016 to May 2017, to gather data from participants at three levels of analysis: individual and team level (micro-level), organisational and inter-organisational level (meso-level) and sectoral, national and international level (macro-level). The original aim was to conduct 65 interviews, representing the entire population involved in small satellite projects (i.e. a census and not a sample). However, only 48 interviews were conducted, representing a participation rate of $73.84 \%$.

At the micro and meso levels, 40 mixed (structured and semi-structured) interviews were conducted. Five interviews with representatives of entities involved in satellite capability-building in Algeria and their foreign satellite suppliers, and 35 interviews with members of satellite project teams involved in the hands-on technical training through mentorship. The targeted number of interviews was 52 , of which 47 were engineers who participated in the hands-on technical training in the satellite projects, Alsat-1, Alsat-2A \& 2B and Alsat-1B. Eight semi-structured and in-depth interviews were held at both the meso and macro levels. Questions were addressed to representatives from the CSD and the Algerian Space Agency's local partners and top management. To ensure validity and reliability, the questions were sent to the interviewees well before the interviews. They were self-administered in the initial stage, and later they were interviewer-administered. Interviews were administered in French and English, as interviewees use one or both of these languages in their everyday professional activities. Each interview lasted 90-180 minutes. Participants were assured that only aggregate data would be presented, to encourage full disclosure.

\footnotetext{
${ }^{10}$ The academic teams were used later in local Algerian projects (but were not part of the collaborative projects presently under study).
} 
Participant observation was also used as a data collection method. It was conducted by the first author of the present paper, who has worked in the Algerian space sector for the last 16 years at both the technical and managerial levels. Accordingly, his role has been a mixture of participant-as-observer (i.e. involved in space activity, overt observation) and observer-as-participant (i.e. uninvolved in space activity, overt observation) [43, p.88; 44, p.454]. The overlapping roles reflect interrupted involvement, i.e. previous or sporadic engagement over time and revealed identity [45, p.144]. The participatory observation generated data consisting of primary and secondary observations as well as experiential data. Primary observational data relate mainly to proceedings in meetings held between the CSD and suppliers. Secondary observational data relate to a number of informal conversations conducted in the first author's presence. Experiential data relate to perceptions formed by the author during observation.

\section{6-b- Earth observation small satellite architecture}

The knowledge transfer model in this article considers typical Earth observation small satellite architectures, including satellites developed for Algeria [29, 46-49]. A small satellite can be divided into a ground segment and a space segment (Figure 5). The ground segment refers to the components used to operate the satellite once in orbit and to receive and process data such as satellite images. The space segment refers to the satellite itself (or a constellation of satellites like Alsat-2A/B). The satellite comprises a platform which carries one or several payloads consisting of optical instrumentation (e.g. cameras) and related modules used to capture images (e.g. control and processing electronics). The platform provides services through the following subsystems: (i) data handling system or on-board computer $(\mathrm{OBC})$ linked to the majority of satellite subsystems in order to manage satellite operations and complete the objectives of the mission; (ii) attitude and orbit control system (AOCS), consisting of attitude (position and behaviour) modules allowing the attitude of the satellite to be determined and actively controlled; (iii) power system capable of generating, storing and managing the power needed for mission operations; (iv) propulsion system used to move the satellite; and (v) communication system used to communicate with the ground station.

In addition to these components, the ground support equipment is also considered part of the space segment. This includes all electrical and mechanical items and software used to support the assembly, integration and testing of the platform and payload. Typically, this also includes the mechanical ground support equipment (MGSE) and electrical ground support equipment (EGSE). The latter is similar or identical to that of the actual ground segment and is used to test satellite subsystems (e.g. the communication, power and attitude control systems).

The knowledge flow model is applied to three collaborative small satellite projects: Alsat-1, Alsat-2 and Alsat-1B. It was applied to project teams involved in hands-on technical training (through mentorship). Knowledge flow with regard to the ground segment is not evaluated by this model, because all Algerian collaborative projects have focused on the space segment. Ground segments were acquired only to exploit the space segments. No joint development or integration activities were carried out in the ground segments. Eight components of the satellite were identified, and to maintain anonymity and confidentiality, they are referred to as $C_{1}, C_{2}, \ldots, C_{8}$. Component identification stems from the fieldwork and takes into account the development philosophies of Alsat-1, Alsat-1B, Alsat$2 \mathrm{~A}$ and Alsat-2B. The structure presented in Figure 5 refers only to a subsumptive containment hierarchy (or taxonomic hierarchy), which classifies components of a "generic" satellite [70]. 
Figure 5: Small satellite structure

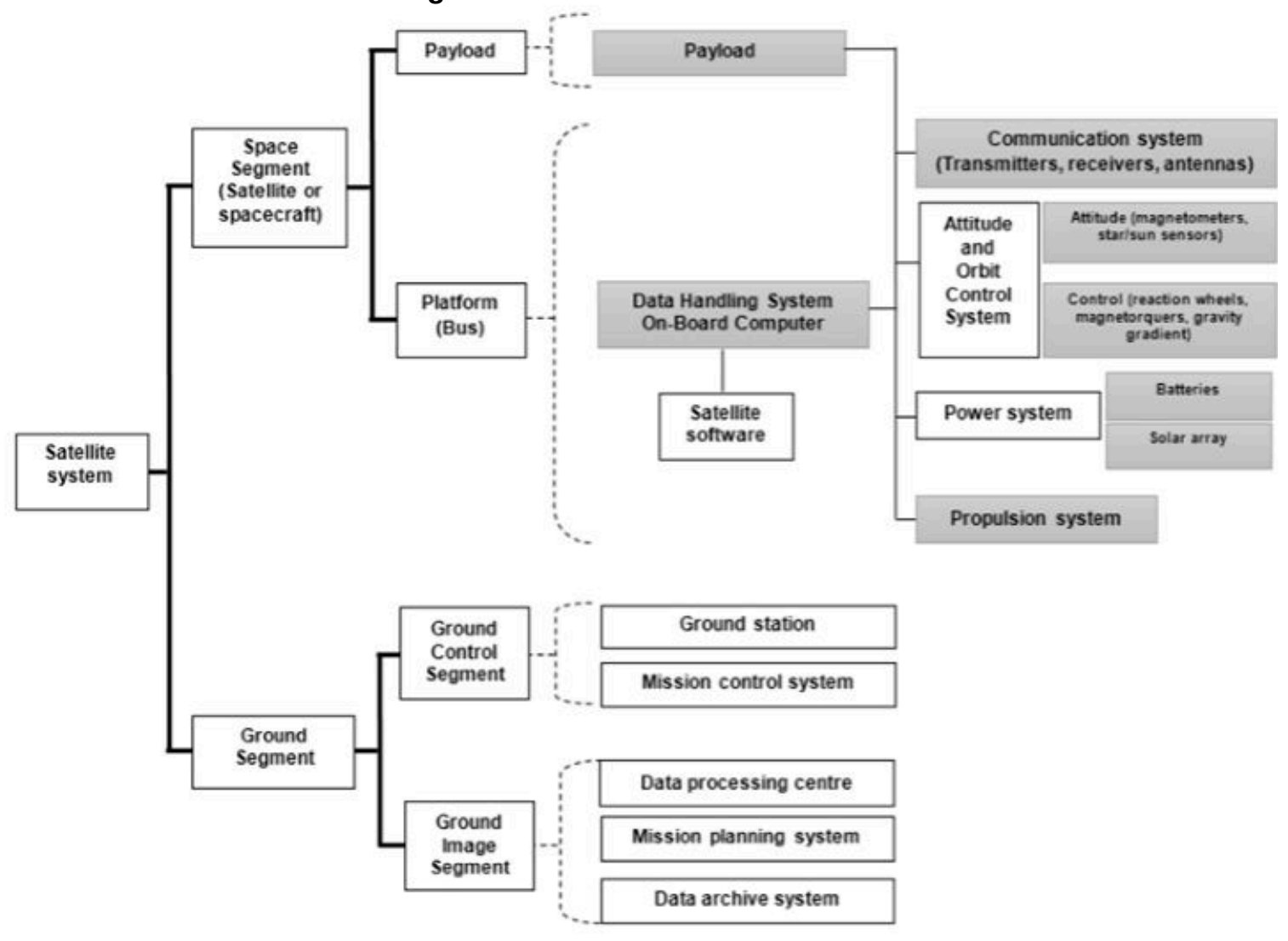

Source: Authors

\section{6-c- Application of the model to the Alsat-1 project}

As shown in Section 5 (Equation (11)), the transferred knowledge equates to $\mathrm{KT}_{0}=\mathrm{KVis}_{0}+\mathrm{KVel}_{0}$. $\mathrm{KVis}_{0}=\mathrm{I}_{0}$, providing an indication of the depth of integrative knowledge required to put satellite components $C_{1}, C_{2}, \ldots, C_{8}$ together. Furthermore, $\mathrm{KVel}_{0}=\mathrm{C}_{1}+\mathrm{C}_{2}+\ldots+\mathrm{C}_{8}$, providing an indication of the breadth of knowledge transferred during the project's lifetime. This is reflected in the number and/or diversity of components involved in the transfer process, along with the depth of knowledge associated with each component.

The following calculations aim to measure three quantitative findings: the depth of integrative knowledge (KViso) and the breadth of knowledge $\left(\mathrm{KVel}_{0}\right)$ in this section $(6-\mathrm{c})$, as well as the transferee absorptive capacity (AC) in section 6-e. It is worth recalling that the focus of the proposed model is not how fast did engineers learn. The focus is what did they learn (the type and quantity/volume of knowledge). The concepts of Viscosity and Velocity are rarely operationalised in the technology management and innovation literature. In the proposed operationalisation, these concepts are not used as a measurement of "speed" in which there is a need to incorporate the requirement of "time". Instead, the knowledge that flows as a result of viscosity (KVis), and velocity (KVel) is used (footnotes 4 and 5 in section 5 highlight caveats so as to avoid misunderstanding). This is why the knowledge transferred (KT) for each component of the system is given by the equation (10): KT (as a metric of a quantity or volume of knowledge) $=\mathrm{KVis}$ (as a metric of a quantity or volume of knowledge, and not speed) + KVel (as a metric of a quantity or volume of knowledge, and not speed). 


\section{Measuring the depth of integrative knowledge:}

The depth of integrative knowledge is measured using two metrics: the intensity of interactions between Algerian team members (as a proxy for group work), and their degree of involvement during the project in the integration and test operations. The average of these two measures (giving equal weight to each metric) is calculated as the value of integrative knowledge.

With regard to the intensity of interactions, the $\mathrm{N}^{2}$ diagram (Figure 6 ) is used to illustrate interactions. This matrix is built by the components of the studied satellites arrayed along rows and columns. The interactions between individuals or teams in charge of these components are recorded in the cells. If the individual or team in charge of the component $C_{i}$ receives inputs (or information) from $C_{j}$, then the cell $(i, j)$ is shaded. If the individual or team in charge of the component $C_{i}$ provides outputs (or information) to $C_{j}$, then the cell $(j, i)$ is shaded. The interaction is not symmetric unless $C_{i}$ receives inputs from $C_{j}$ and provides outputs to $C_{j}{ }^{11}$

This matrix is compiled from the analysis of the individual/team work packages and tasks, ${ }^{12}$ substantiated by responses to interview questions about joint tasks during the course of the project (e.g. what are your interactions with individuals or teams working on other components? What are the inputs you received from them? What are the outputs you send to them? How frequent are these interactions? How deep are these interactions?). As mentioned in section 6-a, to ensure validity and reliability, the questions were sent to the interviewees well before the interviews. They were selfadministered at the initial stage, but later were interviewer-administered. The shaded cells in the matrix indicate interactions between components (or the individuals or teams in charge of them). ${ }^{13}$

Interactions for each project are assigned values from 0 (low) to 1 (high). The following assumption is made: when the interaction value tends towards 0 , it means that Algerian engineers (as learners) work separately without interactions. On the other hand, when the interaction value tends towards 1 , it means that interaction is very intense. This interaction is expressed by the ratio: number of shaded cells/total cells. ${ }^{14}$ For Alsat-1 team members, the final score is calculated as the number of shaded cells divided by the total number of cells $(19 / 64=0.29)$

Figure 6: Interaction matrix for the Alsat-1 project

\footnotetext{
${ }^{11}$ These interactions do not include any parameters other than "inputs" and "outputs".

${ }^{12}$ Work packages are documents describing tasks undertaken by members of the project.

${ }^{13}$ If more than one individual is in charge of a component, an average value is calculated (giving equal weight to all individuals).

${ }^{14}$ We choose to include the matrix diagonal, implying that an individual or team in charge of a component interacts with itself.
} 


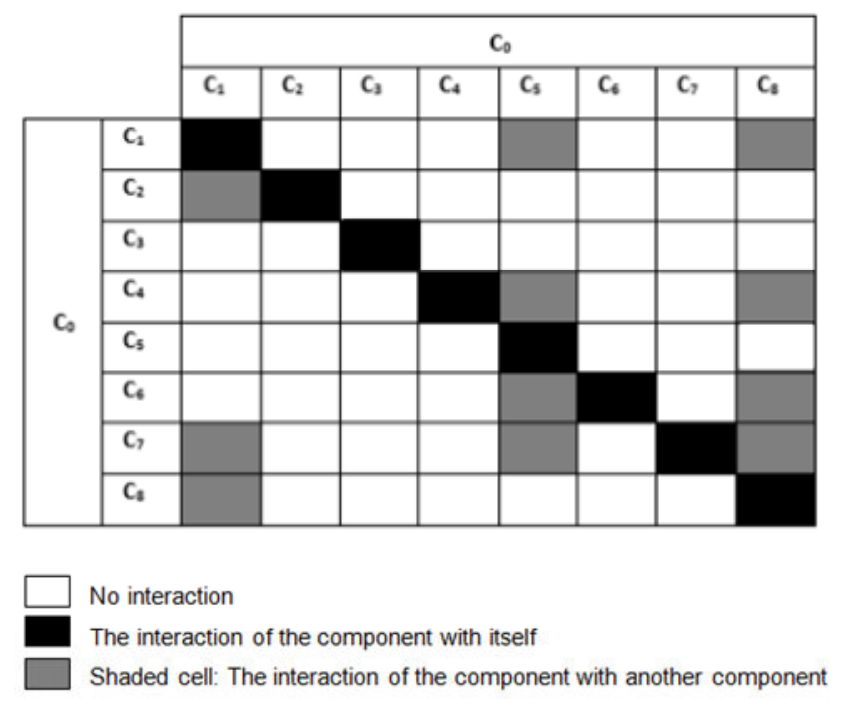

Source: Authors

To ascertain degree of involvement during integration (i.e. putting components together) and testing operations, each team member was asked to quantify their level of involvement during the project (through the Likert scales). On a scale of 0-to-1, the participants gave an average rating of 0.37.

Integrative knowledge was calculated as the average intensity of interaction and degree of involvement in integration and test operations. Consequently, the depth of integrative knowledge for Alsat-1B was calculated as follows:

$\mathrm{KVis}_{0}=\mathrm{I}_{0}=($ interaction score + involvement score $) / 2=(0.29+0.37) / 2=0.33$

\section{Measuring the breadth of knowledge:}

The transferred component knowledge, or breadth of knowledge transfer, during the project is reflected by the number and/or diversity of components involved in the transfer process, along with the depth of knowledge associated with each component.

Eight components were used in the Alsat-1 project, corresponding to the highest component score $(=1)$. This means that there were eight components that could be learned about (i.e. $C_{1}, C_{2}, \ldots, C_{8}$ ). With respect to the depth of knowledge associated with each component, it was determined by comparing the number of Algerian engineers who participated in the development of each component to the number of engineers required for the development, ceteris paribus. ${ }^{15}$ It was difficult to collect data about the number of engineers required for the development of each component (mainly because the mandates of the required engineers overlapped and it was easy to get confused). ${ }^{16}$ To overcome this constraint, an aggregated metric was used, namely the number of Algerian engineers who participated in the development of all components compared to the number of engineers required for the development of all components. According to the participants interviewed from the transferor and transferee's side, 65 individuals were typically required by SSTL-UK to build all the

\footnotetext{
${ }^{15}$ For simplicity and practicality, it is assumed that transferee and transferor's engineer have the same absorptive capacities (i.e. same prior knowledge and intensity of effort).

${ }^{16}$ In general, Algerian engineers didn't rotate and worked on the same satellite component throughout their time. This is due to their background, their low number and the limited exposure to the system (duration of the project).
} 
components of the system, whereas only eight Algerian engineers took part in this project. This gives the following ratio:

number of Algerian engineers/the required number $=8 / 65=0.14$

Consequently, breadth of knowledge for Alsat-1 could be calculated as follows:

$\mathrm{KVel}_{0}=$ actual number of participants $/$ required number of participants $=8 / 65=0.14$

\section{Graphical representation of the knowledge flow:}

The transferred knowledge for the Alsat-1 satellite can therefore be calculated as follows:

$\mathrm{KT}_{0}=\mathrm{KVis}_{0}+\mathrm{KVel}_{0}=0.33+0.14=0.47$ (Figure 7)

Figure 7: Knowledge flow in the Alsat-1 project

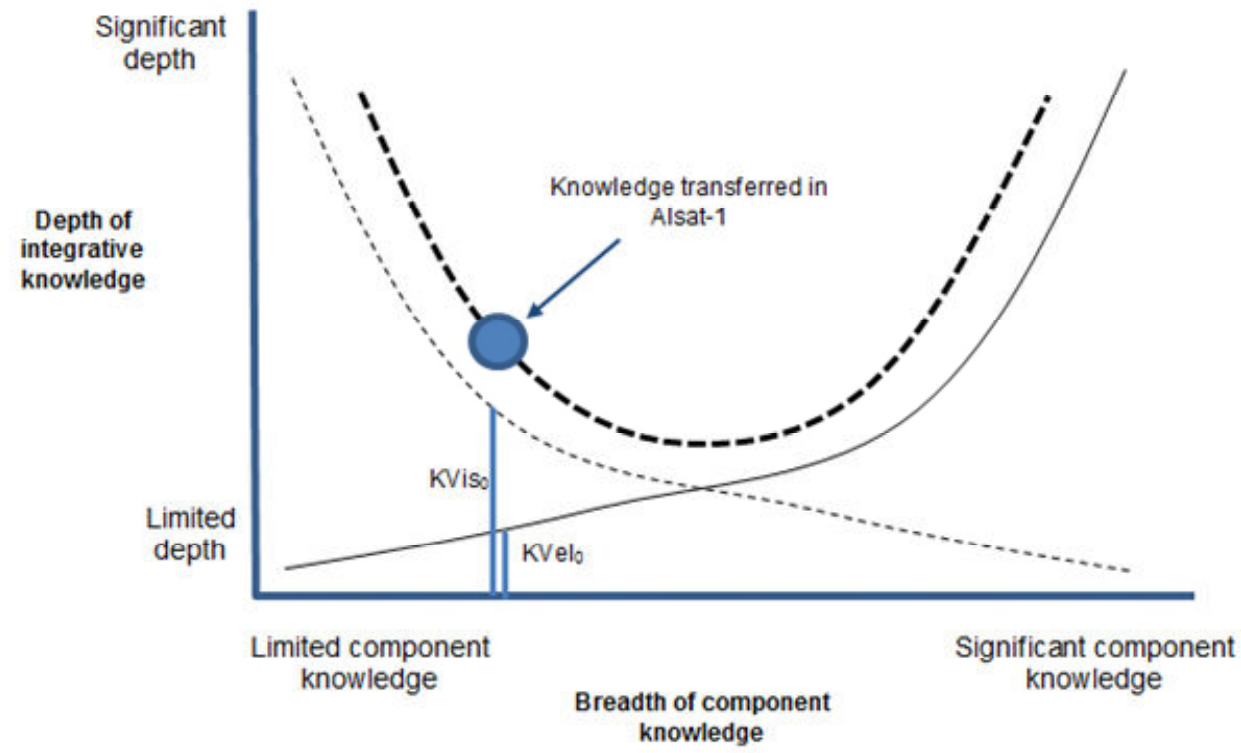

Source: Authors

\section{6-d- Application of the model to the Alsat-2 and Alsat-1B projects}

The steps outlined above for the application of the model to the Alsat-1 project were subsequently applied to the Alsat-2 and Alsat-1B projects. Table 1 summarises the value of the transferred knowledge according to the proposed model. Figure 8 shows interaction matrices for Alsat- 2 and Alsat-1B. 
Table 1: Knowledge flow values for the Alsat-2 and Alsat-1B projects

\begin{tabular}{|c|c|c|c|}
\hline \multicolumn{2}{|c|}{ Alsat-2 } & \multicolumn{2}{|r|}{ Alsat-1B } \\
\hline \multirow{2}{*}{$\begin{array}{l}\text { KViso } \\
\text { Depth of integrative } \\
\text { knowledge } \\
(0.25+0.90) / 2=0.57\end{array}$} & Intensity of interaction $=0.25$ & \multirow{2}{*}{$\begin{array}{l}\text { KVis } \\
\text { Depth of integrative } \\
\text { knowledge } \\
(0.5+0.65) / 2=0.57\end{array}$} & Intensity of interaction $=0.5$ \\
\hline & Degree of involvement $=0.90$ & & Degree of involvement $=0.65$ \\
\hline \multirow{2}{*}{$\begin{array}{l}\mathrm{KVel}_{0} \\
\text { Breadth of knowledge } \\
=0.11\end{array}$} & Number of components $=7^{*}$ & \multirow{2}{*}{$\begin{array}{l}\text { KVel }_{0} \\
\text { Breadth of } \\
\text { knowledge }=0.18\end{array}$} & Number of components $=8$ \\
\hline & $\begin{array}{l}\text { The ratio number of Algerian } \\
\text { engineers/the required } \\
\text { number }=8 / 70=0.11\end{array}$ & & $\begin{array}{l}\text { The ratio number of Algerian } \\
\text { engineers/the required number }= \\
13 / 70=0.18\end{array}$ \\
\hline Prior knowledge & $0.62 * *$ & Prior knowledge & $0.78 * *$ \\
\hline \multicolumn{2}{|c|}{$\mathrm{KT}_{0}=\mathrm{KVis}_{0}+\mathrm{KVel}_{0}=0.57+0.11=0.68$} & \multicolumn{2}{|c|}{$\mathrm{KT}_{0}=\mathrm{KVis}_{0}+\mathrm{KVel}_{0}=0.57+0.18=0.75$} \\
\hline
\end{tabular}

* Calculations are based on a 7x7 matrix.

** See section 6-e for calculations.

Source: Authors

Figure 8: Interaction matrices for the Alsat-2 and Alsat-1B projects

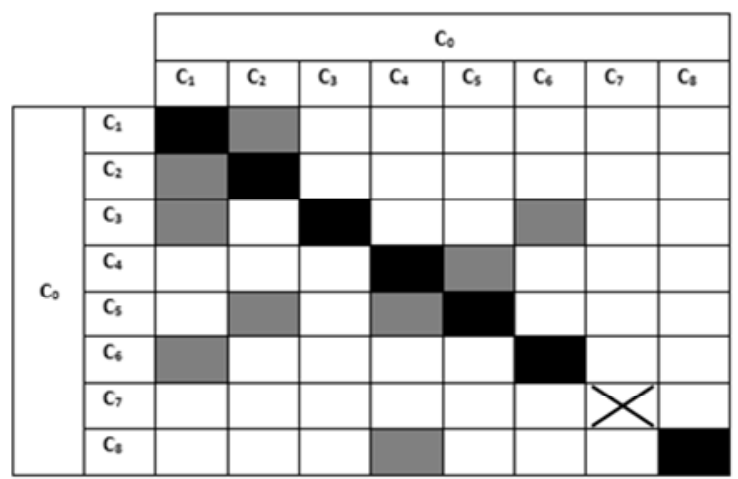

Alsat-2

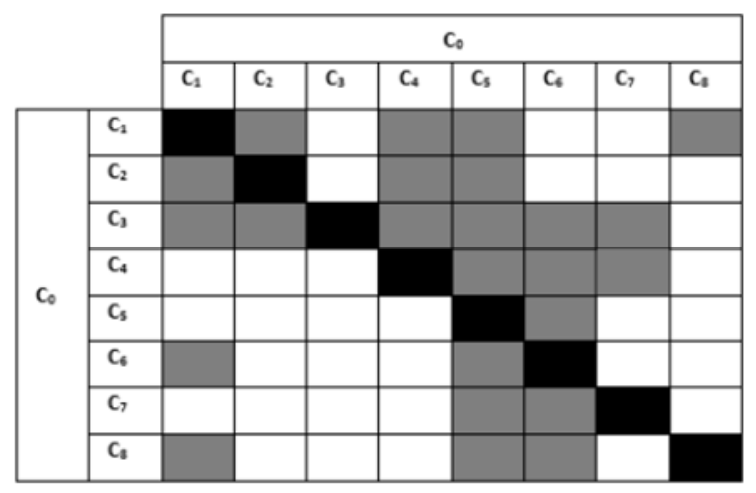

Alsat-1B

\section{No interaction}

Х The component does not exist in the satellite

The interaction of the component with itself

Shaded cell: The interaction of the component with another component

Source: Authors

Based on the values in Table 1, the knowledge flow during the Alsat-2 and Alsat-1B projects can be graphically represented as shown in Figures 9 and 10. 
Figure 9: Knowledge flow in the Alsat-2 project

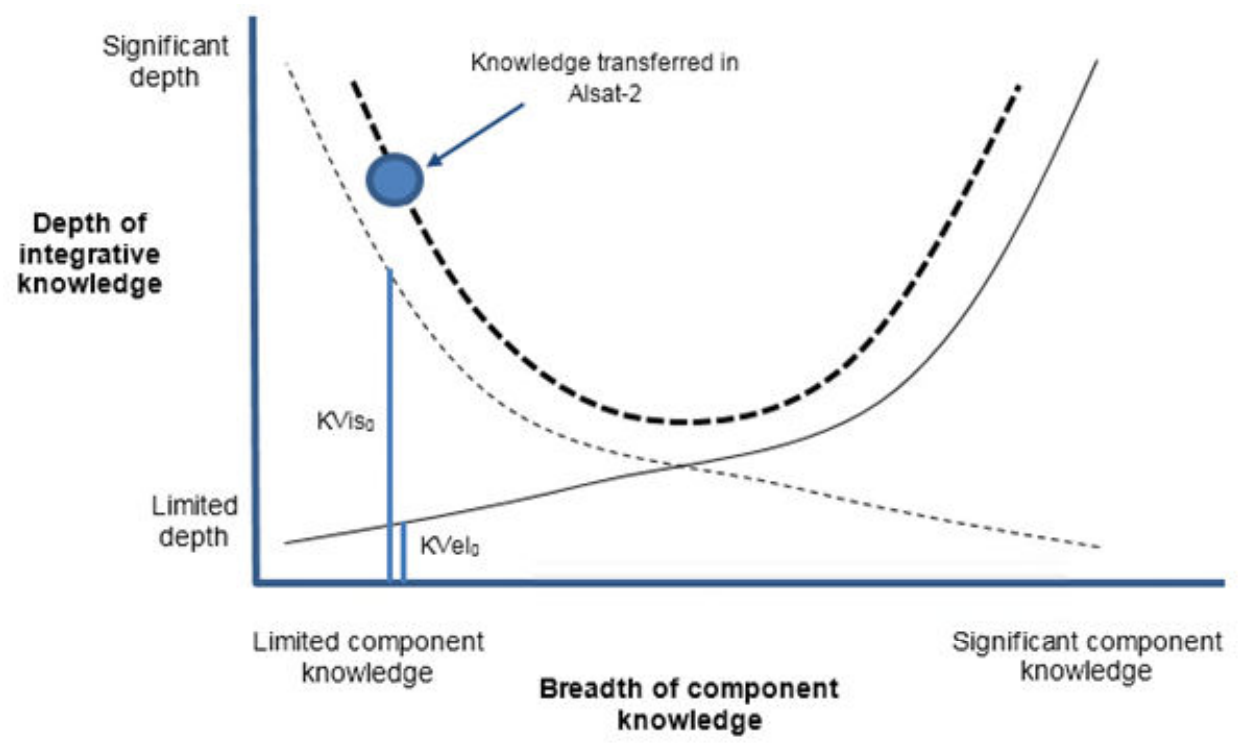

Source: Authors

Figure 10: Knowledge flow in the Alsat-1B project

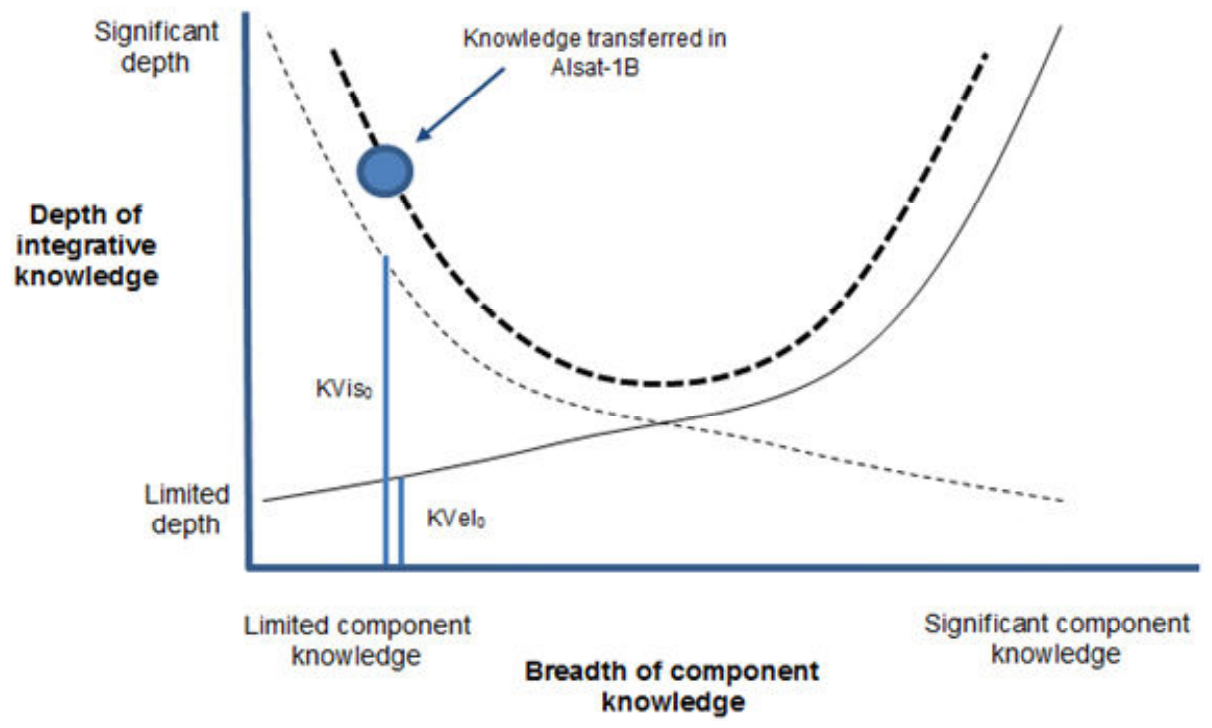

Source: Authors

\section{6-e- Impact of transferee absorptive capacity on knowledge flow}

The graphical representation of the knowledge flow model applied to the three projects shows that there are shifts in terms of initial values on the ordinate axis. These shifts relate to the initial value of knowledge. These shifts are denoted IV (for Initial Value) and are highlighted in Figure 11. Even though the shifts are not significant, the graphical representation shows that $I V_{\text {Alsat-1B }}>I V_{\text {Alsat-2 }}>I V_{\text {Alsat-1. }}$. 
Figure 11: Effect of absorptive capacity in the Alsat-1, Alsat-1B and Alsat-2 projects

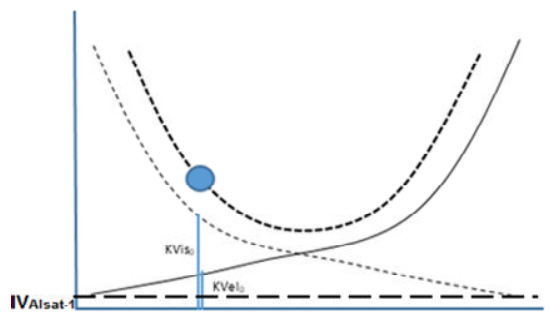

Alsat-1

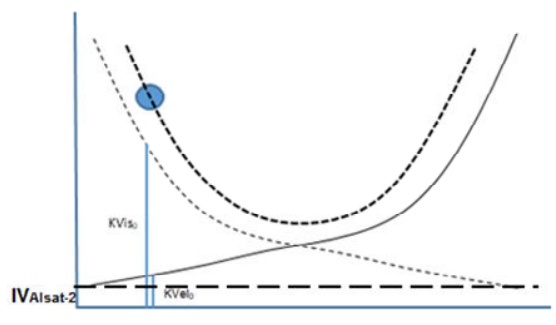

Alsat-2

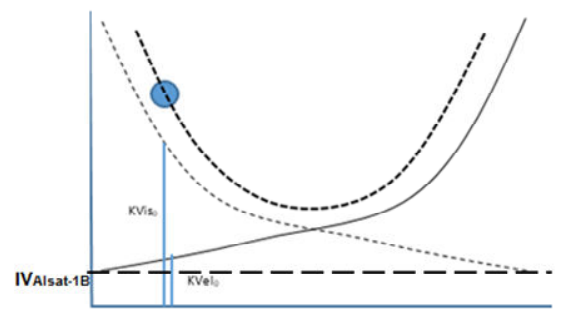

Alsat-1B

Source: Authors

These data suggest that the initial value of knowledge correlates with the absorptive capacity of learners involved in the satellite projects. The value of the absorptive capacity of learners is estimated below, where AC denotes absorptive capacity. According to Cohen and Levinthal [26], the absorptive capacity of learners is reflected through the prior knowledge possessed by the learner (denoted by PK) and the intensity of effort invested in the learning process (denoted by Inty).

$A C=P K+$ Inty

Prior knowledge (PK) is measured by evaluating the appropriateness of the academic and professional backgrounds of project participants, the appropriateness of preparatory activities ahead of the project, and the appropriateness of knowledge possessed against requirements during the project (through the Likert scales). On a scale of 0 -to-1, the average PK ratings of the three projects were $\mathrm{PK}_{\text {Alsat- } 1}=0.58, \mathrm{PK}_{\text {Alsat }-2}=0.62$, and $\mathrm{PK}_{\text {Alsat }-1 \mathrm{~B}}=0.78$.

With regard to the intensity of the learning effort, it is important to recall that technological knowledge includes two complementary elements: tacit and explicit knowledge $[9,10]$. Intensity of effort is therefore a combination of the intensity of tacit learning and the intensity of explicit learning. Because it is difficult to estimate the two elements and their appropriate combination quantitatively, the intensity of effort during the three projects was assumed to be similar. Consequently, the learners' absorptive capacity is reflected only by their prior knowledge in each project. The prior knowledge in Alsat-1B $\left(\mathrm{PK}_{\text {Alsat-1B }}=0.78\right)$ was more significant than that in Alsat-2 $\left(\mathrm{PK}_{\text {Alsat-2 }}=0.62\right)$ and Alsat-1 $\left(\mathrm{PK}_{\text {Alsat- }}\right.$ ${ }_{1}=0.58$ ). The increased value over time reveals a tendency towards improving prior knowledge of the project participants. This was confirmed, as managerial-level participants in this empirical study have observed improvements in the selection of team members and their preparation for the project, through for instance, selection of recent top graduated engineers along with longer preparatory activities for the project.

\section{7- Discussion}

The application of the knowledge flow model to the three Algerian small satellite collaborative projects was only possible at the upper level of the decomposition-integration process (Figure 12). No significant activities were measured at lower levels because the model was not applicable, given that only a few of the transferee's engineers worked at component levels $S_{1}, S_{2}, \ldots, S_{n}$. Thus, it was not possible to measure the architectural/component knowledge pairs at these levels. In other words, 
knowledge that flows as a result of velocity and viscosity was only measured at the upper level $S_{0}$ (Figure 12).

Figure 12: Upper level of the decomposition-integration process

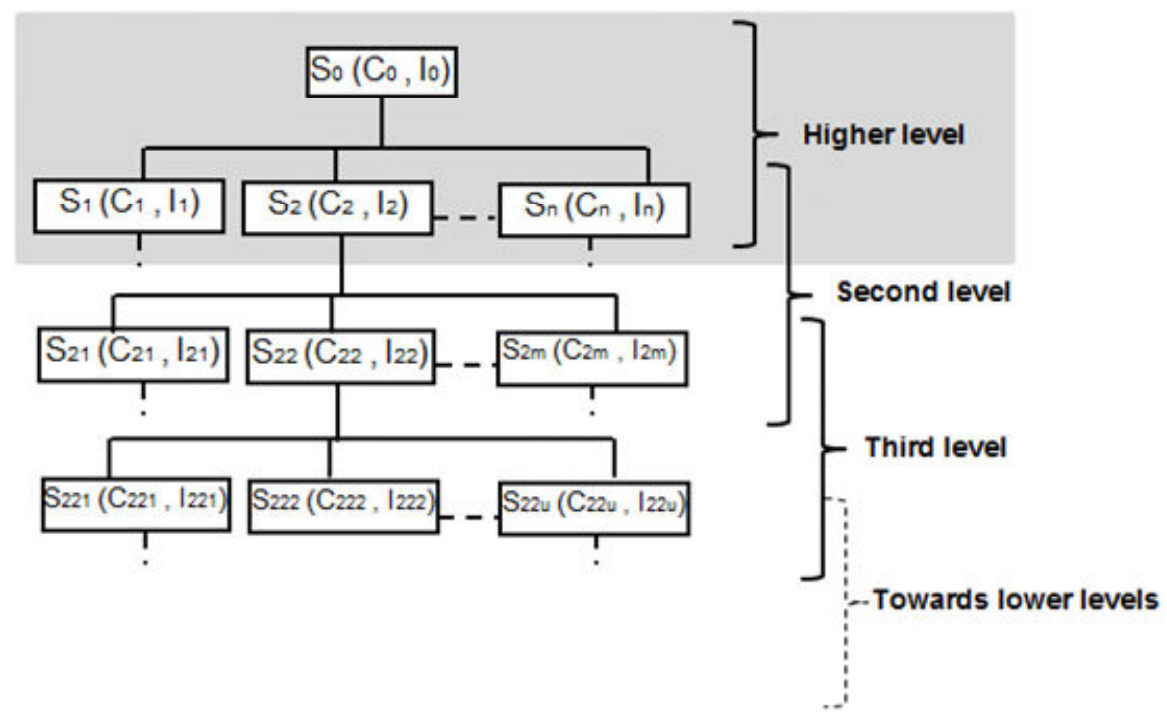

Source: Authors

The application of the model reveals that Algerian teams involved in the process slightly improved their level of architectural knowledge as required for the integration of small satellites. Figures 7, 9 and 10 illustrate the increase in terms of architectural knowledge (or knowledge that flows as a result of viscosity $\mathrm{KVis}$ ). However, component knowledge (or knowledge that flows as a result of velocity $\mathrm{KVel}_{0}$ ) remained limited across all projects. This result matches the responses received during managerial-level interviews regarding the knowledge acquired by Algerian teams. Indeed, the interviewees highlighted the fact that, unlike the initial satellites (Alsat-1 and Alsat-2A), the Algerian teams locally integrated the two subsequent satellites (Alsat-2B, and Alsat-1B) at Algerian facilities, demonstrating greater independence. The interviewees emphasise that the integration process was carried out under minimal supervision from transferor representatives, a deliberate move intended to enhance local team confidence.

On the other hand, responses concerning the ability to build components locally (i.e. acquiring component knowledge at lower levels in Figure 12 such as $\left.S_{2}, S_{21}, S_{22} \ldots\right)$ were less categorical. At the individual and team levels, there was a general consensus that human resources were well below the requirements for building such components. Interviewees reported that only $14 \%$ of the human resources required for component development were allocated to the projects. Consequently, due to the low number of individuals taking an active part, the absorptive capacity of the acquirer was limited from the outset. The limited number of Algerian engineers, added to the constrained duration of the projects, prevented them from engaging in work rotation on other satellite components that could have given them multi-component vision experience, facilitating the acquisition of more integrative knowledge.

Another aspect that particularly affects component knowledge acquisition is the slight difference in terms of component knowledge (or knowledge that flows as a result of velocity $\mathrm{KVel}_{0}$ ) acquired in projects conducted with SSTL-UK (Alsat-1 and Alsat-1B) and Airbus-France (Alsat-2). Component knowledge in the Alsat-1 and Alsat-1B projects was slightly higher than in Alsat-2, partly due to the company size and business model adopted by the technology transferor. In the Alsat- 1 and Alsat-1B 
projects, the bulk of component development, satellite integration and testing were insourced at SSTL-UK. This high level of vertical integration, which goes a long way towards explaining the durability of SSTL-UK [50], provided an opportunity for Algerian engineers in collaborative projects to be in direct contact with component technology, and to increase their own knowledge. On the other hand, data collected on the Alsat-2 project highlight that the Airbus approach to building satellites is different. It is a large company which focuses on building integrative knowledge (or knowledge that flows as a result of viscosity flows only at higher level of decomposition/integration) and outsourcing component development [51] ${ }^{17}$ This business model seems to inadvertently steer Algerian participants away from acquiring component knowledge.

With regard to the indigenisation of the acquired knowledge, the data indicate it is premature to broach questions about technological local value creation, for example by establishing a local supply chain. Some initiatives involved local industry as part of collaborative projects to manufacture noncore elements of the satellite system. However, the density and continuity of interactions have been insufficient, and local companies must upgrade to comply with space-industry quality requirements (e.g. specification definition, accuracy, traceability of measurements, test procedures) and management practices. Concerns also extend to the incentives offered by the Algerian Space Agency and the broader policy towards local actors.

Building a local supply chain is also influenced by the technical architecture of the satellite and whether its components can be insourced or outsourced. Algerians acquired a shallow ${ }^{18}$ form of satellite architectural knowledge, mostly oriented around engineering and development. The design knowledge was not the focus of the collaborative project, because each project involved mature technologies inherited from previously approved designs. Rather, the focus was on the project implementation phase [22]. The data revealed that the emphasis in collaborative projects was on developing an integrative knowledge, or a form of architectural knowledge. The latter originates from knowledge of the product design [33, 17], yet design knowledge is largely overlooked in the mechanism of collaborative projects. This may represent one of the main contradictions or limitations of the collaborative mechanism. Another downside is that projects are conducted based on mature technologies held by the transferor. The transferor logic prevails, sometimes reducing the transferee's engineers to the level of trainees without active participation. These limitations can also be explained by the non-alignment of objectives between the transferor and transferee. The transferee was driven by non-economic and developmental goals whereas the transferor was driven by economic goals (profit-seeking). The transferor thus adopts a restrictive posture (e.g. Intellectual property protection) to prevent the risk of technological leakage that might fuel future competition.

\section{8- Conclusion and recommendations}

The Algerian Space Agency uses collaborative projects to acquire small satellite technology from abroad and to build local capability. The implementation of the knowledge flow model revealed that the collaborative projects enabled only the acquisition of a shallow form of architectural knowledge (where the knowledge does not go deeper), detached from the local environment. The findings underscore the limitations of this mechanism and the challenge faced by the CSD to find the appropriate balance of component/architectural knowledge and knowledge 'resulting from' velocity/viscosity across all levels of the decomposition-integration spectrum.

The CSD is a limited-resource organisation. The literature on strategy and innovation suggests, as explained in section 2, that the optimal choice for organisations with limited resources is to narrow

\footnotetext{
${ }^{17}$ Despite the acquisition of SSTL by Airbus Group in 2008, SSTL's approach to building satellites remains different from that of Airbus.

${ }^{18}$ Knowledge that flows as a result of viscosity does not flow beyond the upper level of decomposition/ integration process (it remains shallow).
} 
the scope of their activities. Therefore, one recommendation is that CSD narrows the scope of its activities. A plausible option would be the development of internal satellite design capabilities along with assembly, integration and test capabilities (i.e. deepening the flow of viscosity at upper levels of the satellite system - some architectural knowledge). In parallel, some crucial components should be insourced (i.e. deepening the flow of velocity of a limited number of components - some component knowledge is insourced), whereas non-bottleneck components should be outsourced.

This strategic choice might be perceived as inconsistent with Algeria's objective of generating local value through establishing a national satellite industry. However, assembly, integration, and test operations in the particular case of small satellite technology should not be underestimated and viewed as mere screwdriver operations. The ability to conduct such operations is vital in small satellite development, notably when the industry trend is towards integrating commercial off-the-shelf components, which require little in the way of component knowledge [52]. On the other hand, given the interwoven nature of satellite architectural and component knowledge, and the knowledge that flows from velocity and viscosity, the choice of components to insource should be based on how strongly coupled they are to the architectural capabilities deemed important to build. Further research should address the choice of components for adoption by the technology acquirer and their interplay with both the satellite architecture, and the organisational structure of the technology acquirer. This would require a review of emerging trends in small satellite technology (for which technological forecasting techniques would be critical) and the appropriateness of such trends for developing countries (e.g. characteristics of organisations in developing countries, the mirroring of technical dependencies and organisational ties).

This article is one of a small number of empirical research reports addressing satellite technology development in developing countries at a finer level of aggregation. The proposed knowledge flow model was tested within the setting of small satellites in Algeria. However, it may also be applicable to other complex technologies in different contexts (e.g. transfer from developed-to-developed countries), provided that it can be empirically tested, enriched and adapted through further research.

Finally, it is important to recall that the proposed model can be used to evaluate and characterise the knowledge flow enabled using joint-projects as a technology transfer mechanism, and to guide transfer processes whose success depends on multiple political, socio-economic and organisational factors, as well as exogenous and endogenous factors.

\section{References}

[1] Grant, R.M., 1996. Toward a knowledge-based theory of the firm. Strategic Management Journal $17,109-22$.

[2] Davenport, T. H., Prusak, L., 1998. Working knowledge: How organization manage what they know. Harvard Business School Press, Boston.

[3] Henderson, R.M., Clark, K.B., 1990. Architectural innovation: the reconfiguration of existing product technologies and the failure of established firms. Administrative Science Quarterly 35(1), 9-30. 
[4] Wood, D., Weigel, A., 2014. Architectures of small satellite programs in developing countries. Acta Astronautica 97, 109-21.

[5] Helms, R., Buijsrogge, K., 2005. Knowledge Network Analysis: a technique to analyze knowledge management bottlenecks in organizations. Proceedings of the 16th International Workshop on Database and Expert Systems Applications (DEXA'05), IEEE.

[6] Helms, R., Buijsrogge, K., 2006. Application of knowledge network analysis to identify knowledge sharing bottlenecks at an engineering firm. Proceedings of the 14th European Conference on Information Systems Göteborg, Sweden.

[7] Kim, L., 1997. Imitation to Innovation: The Dynamics of Korea's Technological Learning. Harvard Business School Press.

[8] Lall, S., 1992. Technological capabilities and industrialization. World Development 20 (2), 165-86.

[9] Cowan, R., David, P. A., Foray, D., 2000. The explicit economics of knowledge codification and tacitness. Industrial and Corporate Change 9(2), 211-53.

[10] Marcotte, C., Niosi, J., 2000. Technology Transfer to China: The Issues of Knowledge and Learning. Journal of Technology Transfer 25, 43-57.

[11] Tallman, S., Jenkins, M., Henry, N., Pinch, S., 2004. Knowledge, clusters, and competitive advantage. Academy of Management Review 29 (2), 258-71.

[12] McGaughey, S. L. 2002. Strategic interventions in intellectual asset flows. Academy of Management Review 27, 248-74.

[13] Garud, R., Nayyar, P. R., 1994. Transformative capacity: Continual structuring by intertemporal technology transfer. Strategic Management Journal 15, 365-85.

[14] Brown, J. S., Duguid, P., 2001. Knowledge and organization: A social-practice perspective. Organization Science 12, 198-213.

[15] Matusik, S.F., Hill, C.W.L., 1998. The Utilization of Contingent Knowledge Creation, and Competitive Advantage. Academy of Management Review 23 (4), 680-97.

[16] Nelson, R.R., Winter, S.G., 1982. An evolutionary theory of economic change. Harvard University Press, Cambridge.

[17] Baldwin, C.Y., 2010. When open architecture beats closed: The entrepreneurial use of architectural knowledge. Working Paper, Harvard Business School.

[18] Teece, D.J., 1996. Firm Organization, Industrial Structure, and Technological Innovation. Journal of Economic Behavior and Organization 31(2), 193-224

[19] Jacobides, M.G., Winter, S.G., 2005. The co-evolution of capability and transaction costs: explaining the institutional structure of production. Strategic Management Journal 26(5), 395-413.

[20] Forsberg, K., Mooz, H., Cotterman, H., 2005. Visualizing Project Management: Models and frameworks for mastering complex systems. Third Edition, John Wiley \& Sons, Inc. 
[21] Rycroft, R.W., Kash, D.E., 1999. The Complexity Challenge: Technological Innovation for the 21st Century. Pinter, London.

[22] Hobday, M., Rush, H., 1999. Technology management in complex product systems (CoPS) - ten questions answered. International Journal of Technology Management 17(6), 618-38.

[23] Hobday, M., 1998. Product complexity, innovation and industrial organisation. Research Policy 26, 689-710.

[24] Prencipe, A., 2000. Breadth and depth of technological capabilities in CoPS: the case of the aircraft engine control system. Research Policy 29, 895-911.

[25] Lucchetta, G., Bariani, P.F., Knight, W.A., 2005. Integrated Design Analysis for Product Simplification. CIRP Annals - Manufacturing Technology 54 (1), 147-50.

[26] Cohen, W.M., Levinthal, D.A., 1990. Absorptive Capacity: A New Perspective on Learning and Innovation. Administrative Science Quarterly 35, 128-52.

[27] Kim, L., 1999. Building technological capability for industrialization: analytical frameworks and Korea's experience. Industrial and Corporate Change 8(1), 111-36.

[28] Davies, A., 1997. The Life Cycle of a Complex Product System. International Journal of Innovation Management 01(3), 229-56.

[29] Moody, J.B., Dodgson, M., 2006. Managing complex collaborative projects: Lessons from the development of a new satellite. Journal of Technology Transfer 31(5), 567-88.

[30] Wood, D.R., 2012. Building technological capability within satellite programs in developing countries. PhD Thesis, MIT.7

[31] Lundvall, B., 2007. National Innovation Systems - Analytical concept and development tool. Industry and Innovation 14(1), 95-119.

[32] OECD, 2014. The Space Economy at a Glance 2014. OECD Report (downloaded on 07 February 2015 from http://www.asaspazio.it/wp-content/uploads/2014/11/The-Space-Economy-at-aGlance-2014.pdf )

[33] MacCormack, A., Baldwin, C., Rusnak, J., 2010. The Architecture of Complex Systems: Do Coreperiphery Structures Dominate?. Working Paper, Harvard Business School.

[34] Tybout, J.R., 2000. Manufacturing Firms in Developing Countries: How Well Do They Do, and Why? Journal of Economic Literature 38(1), 11-44.

[35] Metz, B., Davidson, O., Martens, J-W., Van Rooijen, S., Van Wie Mcgrory, L. (Eds.), 2001: Managing Technological Change, An explanatory summary of the IPCC Working Group III Special Report: Methodological and Technological Issues in Technology Transfer, United Nations Environment Programme Division of Technology, Industry and Economics (downloaded on 10 July 2016 from http://www.ipcc.ch/ipccreports/sres/tectran/index.php?idp=0 )

[36] Mansfield, E., 1988. The Speed and Cost of Industrial Innovation in Japan and the United States: External vs. Internal Technology. Management Science, 1157 - 68. 
[37] Prencipe, A., 1998. Modular Design and Complex Product Systems: Facts, Promises, and Questions. Working Paper, CoPS Publication 47.

[38] Novak, S., Eppinger, S. D., 2001. Sourcing by Design: Product Complexity and the Supply Chain. Management Science 47 (1), 189-204.

[39] Ulrich, K.T., Ellison, D.J., 2005. Beyond Make-Buy: Internalization and Integration of Design and Production. Production and Operations Management 14(3), 315-30.

[40] Baldwin, C.Y., Clark, K.B., 2000. Design Rules, Volume 1: The Power of Modularity. MIT Press, Cambridge, MA.

[41] INCOSE, 2006. Systems Engineering Handbook, Version 3, The International Council on Systems Engineering-INCOSE.

[42] Peterson, M.R., Rodberg, E.H., 2005. Spacecraft Integration and Test, in: Pisacane, V.L. (Ed), Fundamentals of Space Systems, Second Edition. Oxford Univerity Press, 725-53.

[43] Guest, G., Namey, E.E., Mitchell, M.L., 2013. Collecting Qualitative Data - A Field Manual for Applied Research. SAGE Publications.

[44] Bryman, A., Bell, E., 2007. Business research method. Second Edition, Oxford University Press.

[45] Easterby-Smith, M., Thorpe, R., Jackson, P., 2012. Management research. Forth Edition, SAGE Publications Ltd.

[46] Bekhti, M., Sweeting, M.N., 2008. Power system design and in orbit performance of Algeria's first micro satellite Alsat-1. Electric Power Systems Research 78(7), 1175-80.

[47] Da Silva Curiel, A., Lambert, M., Liddle, D., Sweeting, M., Chu, C.H., Fong, C.J., Chang, G.S., 2013. Introduction to FORMOSAT-7/COSMIC-2 Mission. 27 $7^{\text {th }}$ Annual AIAA/USU Small Satellite Conference.

[48] Landiech, P., Rodrigues, P. (2010). Overview on CNES Micro Satellites Missions: In flight, Under development and Next, in: Sandau, R., Roeser, H.P., Valenzuela, A. (Eds.), Small Satellite Missions for Earth Observation: New Developments and Trends. Springer, pp. 3-18.

[49] CNES, 2015. Satellite Platform: Myriade. CNES Project library, Centre National des Etudes Spatiales-France (Accessed on 05 October 2016 on https://myriade.cnes.fr/en/MYRIADE/index.htm)

[50] Cookson, C., 2015. Guildford's SSTL leads world in small satellite supply. Financial Times, June 12, 2015. https://www.ft.com/content/076f6374-0944-11e5-b643-00144feabdc0

[51] Petroni, G., Santini, S., 2012. Innovation and change? The evolution of Europe's small satellite manufacturers. Space Policy 28, 25-32.

[52] Sandau, R., 2010. Status and trends of small satellite missions for Earth observation. Acta Astronautica 66(1-2), 1-12. 
[53] Colfer, L.J., Baldwin, C.Y., 2016. The mirroring hypothesis: theory, evidence, and exceptions. Industrial and Corporate Change 25(1), 709-38.

[54] Browning, T.R., 2001. Applying the Design Structure Matrix to System Decomposition and Integration Problems: A Review and New Directions. IEEE Transactions on Engineering Management 48(3), $292-306$.

[55] Petroni, G., Venturini, K., Santini, S., 2010. Space technology transfer policies: Learning from scientific satellite case studies. Space Policy 26, 39-52.

[56] Venturini, K., Verbano, C., 2014. A systematic review of the Space technology transfer literature: Research synthesis and emerging gaps. Space Policy 30, 98-114.

[57] Jason, S., Curiel, A., Liddle, D., Chizea, F., Leloglu, U.M., Helvaci, M., Bekhti, M., Benachir, D., Boland, Lee., Gomes, L., Sweeting, M., 2010. Capacity building in emerging space nations: Experiences, challenges and benefits. Advances in Space Research 46, 571-581.

[58] Leloglu, U.M., Kocaoglan, E., 2008. Establishing space industry in developing countries: Opportunities and difficulties. Advances in Space Research 42, 1879-1886.

[59] Schwartz, D., Divitini, M., Brasethvik, T. (Eds), 2000. Internet-Based Organizational Memory and Knowledge Management. 1st Edition, Idea Group Publishing.

[60] Lee, J.J., Chung, S., 2011. Space policy for late comer countries: A case study of South Korea. Space Policy 27, 227-233.

[61] Park, W.H., 2010. Recent space developments in South Korea. Space Policy 26, 117-118.

[62] Argoun, MB., 2012. Recent design and utilization trends of small satellites in developing countries. Acta Astronautica 71, 119-128.

[63] Rosenkopf, L., Shilling, M.A., 2007. Comparing Alliance Network Structure across Industries: Observations and Explanations. Strategic Entrepreneurship Journal 1, 191-207.

[64] Fixson, S.K., 2005, Product Architecture and Assessment: A Tool to Link Product, Process, and Supply Chain Design Decisions. Journal of Operations Management 23, 345-369.

[65] Denzin, N.K., 2009. The Research Act: A Theoretical Introduction to Sociological Methods. Published by Aldine transaction, pp.301-313.

[66] Wasserman, S. and K. Faust. (1994). Social Network Analysis: methods and applications. Cambridge University Press.

[67] R. van der Spek, J. Hofer-Alfeis, J. Kingma, The knowledge strategy process, in: C.W. Holsapple (Ed.), Handbook on Knowledge Management 2: Knowledge Directions, Springer-Verlag, Heidelberg, 2003, pp. 443-466.

[68] Bhagat, R.S., Kedia, B.L., Harveston, P.D., Triandis, H.C., 2002. Cultural Variations in The CrossBorder Transfer Of Organizational Knowledge: An Integrative Framework. Academy of Management Review 27(2), 204-221. 
[69] Kedia, B. L., Bhagat, R. S., 1988. Cultural Constraints on Transfer of Technology Across Nations: Implications for Research in International and Comparative Management. Academy of Management Review 13 (4), 559-571.

[70] Zafeiris, A., Vicsek, T., 2018. Why We Live in Hierarchies? A Quantitative Treatise. Springer Briefs in Complexity.

[71] Wernerfelt, B., 1984. A Resource-Based View of the Firm. Strategic Management Journal 5(2), 171-180.

[72] Alvarez, S.A., Busenitz, L.W., 2001. The Entrepreneurship of Resource-Based Theory. Journal of Management 27, 755-775.

[73] Sakuma, A., (1995). The dynamics of innovation and learning-by-doing: the case of the integrated circuit industry, in: Minami, R., Makine, H., Soe, J. (Eds.), Acquiring, adapting and developing technologies. London: St. martin's, pp.165-190.

[74] Stewart, F., (1992). North-South and South-South. Palgrave Macmillan UK.

[75] Ruttan, V., Hayami, Y., 1973. Technology transfer and agriculture development. Technology and culture 14(2), 119-150.

[76] SIA, 2016. State of the Satellite Industry Report 2016, Satellite Industry Association, The Tauri group, pp.7-18.

[77] Ayad, A., Wilkinson, E, Matthews, R., 2019. Systemic experiential learning model for the evaluation of technological learning: the case of small satellite capability-building in Algeria. Intrenational journal of technology management and sustainable development 18(1), 75-100.

[78] Bellù, L.G., 2011. Development and Development Paradigms: A (Reasoned) Review of Prevailing Visions. EASYPol - Resources for policy making, Food and Agriculture Organization of the United Nations, pp.1-46.

[79] Piraveenan, M. 2019. Applications of Game Theory in Project Management: A Structured Review and Analysis. Mathematics 7(9), 1-31. 